\title{
Cuticle Secretion Duration in the Uterus Is One of the Major Factors Affecting Eggshell Cuticle Deposition in White Leghorn Laying Hens
}

\section{Xia CHEN}

China Agricultural University

\section{Zhaoxiang HE}

China Agricultural University

\section{Xingzheng LI}

China Agricultural University

Jianlou SONG

China Agricultural University

Mingyi HUANG

China Agricultural University

\section{Xuefeng SHI}

China Agricultural University

\section{Xianyu LI}

China Agricultural University

Junying LI

China Agricultural University

\section{Guiyun XU}

China Agricultural University

\section{Ning YANG}

China Agricultural University

Jiangxia ZHENG ( $\sim$ jxzheng@cau.edu.cn)

China Agricultural University https://orcid.org/0000-0001-7464-3154

\section{Research article}

Keywords: Cuticle, Eggshell quality, Uterus, Transcriptome, Proteome, Laying rhythm, Laying hen

Posted Date: December 11th, 2020

DOI: https://doi.org/10.21203/rs.3.rs-124583/v1 
License: (c) (i) This work is licensed under a Creative Commons Attribution 4.0 International License. Read Full License 


\section{Abstract}

Background: The cuticle formed in the uterus is the outermost layer as the first defense line of eggshell against microbial invasions in most avian species, and analyzing its genetic regulation and influencing factors are of great importance to egg biosecurity in poultry production. The current study compared the uterine transcriptome and proteome of laying hens producing eggs with good and poor cuticle deposition (GC and PC, the top and tail of the cuticle deposition distribution), and identified several genes involved with eggshell cuticle deposition.

Results: Overall, transcriptomic analysis identified 53 differentially expressed genes (DEGs) between PC vs GC group hens, among which 25 were up-regulated and 28 were down-regulated. No differences were found in the uterine proteome. Several up-regulated DEGs of PC vs GC hen uterus, including PTGDS, PLCG2, ADM and PRLR related to uterine functions and reproductive hormones, were validated by qPCR analysis. Phenotypic measurements for verification between GC and PC hens showed GC hens had longer laying interval between two consecutive ovipositions ( $25.64 \pm 1.23$ vs $24.94 \pm 1.12 \mathrm{~h}$ ), thicker eggshell thickness $(352.01 \pm 23.04$ vs $316.20 \pm 30.58 \mu \mathrm{m})$ and more laying days $(20.67 \pm 2.58$ vs $18.48 \pm$ $2.46)$ within 27 laying days $(P<0.05)$. Apart from eggshell traits, other egg quality traits didn't differ. The results above suggested that the expression patterns of PTGDS, PLCG2, ADM and PRLR genes in the uterus regulated the muscular activity rhythm and secretion function, which ensured the eggshell and cuticle formation duration, and lead to the good eggshell and cuticle quality of the GC hens.

Conclusions: The present study demonstrated eggshell and cuticle secretion duration in the uterus is one of the major factors affecting eggshell cuticle deposition in laying hens. PTGDS, PLCG2, ADM and PRLR genes were discovered and might play crucial roles in cuticle deposition by regulating the uterine muscular activities and secretion function. Moreover, the cuticle is associated with the eggshell quality and laying performance, implying the importance of selection to the cuticle trait in laying hens. The findings in present study provide new insights into the genetic regulation of cuticle deposition in laying hens and establish a foundation for further investigations.

\section{Background}

The annual Global Report on Food Crises 2020 by the Food Security Information Network (FSIN) indicates that the world is facing an unprecedented food crisis [1]. As a source of low-cost and highquality animal protein, poultry production not only meets the basic nutritional needs of humans, but also is an important contributor to the economies and cultures, and thus the demand for poultry egg and meat is increasing [2]. Egg safety is absolutely pivotal to the success of today's poultry industry, however, egg contamination with pathogenic bacteria is considered one of the leading causes of economic loss in the poultry industry worldwide and represents a threat to public health $[3,4]$. Furthermore, faced with current environmental pressures and animal welfare requirements, the modern poultry industry, which relies on the extensive use of artificial incubation, is more dependent on strict biosecurity of the egg [5]. 
Avian eggshells have evolved multiple physical and chemical barriers in response to microbial challenges, and these barriers are essential for the successful reproduction of avian species as well as to maintain safe and nutritious table eggs for human consumption [6, 7]. The eggshell is a complex with several highly ordered and distinct layers (i.e., mammillae, palisades, vertical crystal layer, and cuticle) and the cuticle is the outermost layer as the first defense line of the eggshell against microbial invasions in most avian species [8-10]. The cuticle has been a relatively neglected structure while recent researches on the properties, composition, functions, physiology and genetics of the cuticle have highlighted its important role in ensuring egg biosecurity and quality in poultry production. The cuticle is deposited during the final hr of egg formation in the uterus (shell gland pouch), covering the shell surface and filling the external openings of the gas pores so that effectively exerting waterproof and antibacterial effects $[11,12]$. The cuticle mainly consists of hydroxyapatite crystals, glycoprotein, polysaccharides, lipids, and pigment $[13,14]$, and abundant antibacterial proteins (e.g., lysozyme C, ovotransferrin, ovocalyxin-32, ovocleidin-17) constitute the molecular basis for the antimicrobial function of the cuticle $[15,16]$. It has been demonstrated that good cuticle deposition of the eggshell can significantly reduce the opportunity of pathogen invasion $[5,17,18]$, and the quantity of cuticle is a heritable trait that genetic selection to this trait can be an effective strategy to reduce transmission of microorganisms in poultry production $[8,19]$. Therefore, how to improve cuticle deposition to ensure egg biosecurity and quality and further promote poultry production has drawn a worldwide interest.

Avian birds are oviparous and produce an egg at intervals precisely controlled by the hormonal secretion and gene expression of the hypothalamo-pituitary-gonadal-oviduct axis [10,12, 20-22]. Previous transcriptomic and proteomic studies of hen (Gallus gallus) reproductive tract have well profiled the temporal and spatial transcriptome landscapes and important genes that regulate egg formation [2228]. Cuticle deposition is also a well-defined and specific process that occurs in the uterus rather than the extension of mineralized eggshell [12]. It's reported that there is a significant association between ovocleidin-116, ovocalyxin-32, ovalbumin, and estrogen receptor (ESR1) genes and cuticle deposition [8, 29]. Transcriptome analysis of the uterus of hens laying eggs with good or poor cuticle deposition suggested that clock genes and immediate early genes are prime candidates for the control of cuticle deposition and the uterus transcriptome did not differ that the genetic effects of cuticle deposition might not be expressed in the uterus [30]. However, there is few duration for the secretion of the cuticle compared with other components of the egg, making it difficult to exactly obtain the uterine tissue and the transcriptomic and proteomic data during cuticle deposition. Thus, specific pathways and genes that regulate cuticle deposition still remain unclear.

In present study, transcriptomic and proteomic status of uterus from White Leghorn laying hens that produced eggs with good and poor cuticle deposition (GC and PC, the top and tail of the cuticle deposition distribution) were analyzed to identify unknown candidate regulatory genes involved in eggshell cuticle deposition and provide deeper insights into the biological basis of cuticle deposition. This is also an accurate study to describe the uterus transcriptome and proteome during the process of chicken eggshell cuticle formation, providing a reference for further improving the eggshell cuticle deposition in laying hens. 


\section{Results}

\section{Cuticle opacity of eggs from GC and PC hens for transcriptomic and proteomic analysis}

Earlier observations of present study showed that the cuticle quality (a value) may have great variability in the same individual. Therefore, cuticle quality of eggs produced by the experimental flock was monitored for the 14 consecutive laying days to obtain individuals that stably produced eggs with good or poor cuticle deposition (GC or PC) for subsequent sampling and analysis. The cuticle deposition was more abundant in the GC group versus the PC group as indicated by a significant difference in a value (GC $30.18 \pm 7.62$ vs PC $10.34 \pm 3.67$ a value; $n=7$ and 4 , respectively; $F 1,9<0.001$ ). In other words, the GC group hens had a strong ability for cuticle deposition whilst the PC groups hens had almost no secretion of cuticle. MST cuticle blue dye results of eggs taken from uterus of GC and PC hens during sampling demonstrated that the uterus of GC group had secreted a remarkable thicker cuticle layer than PC group (Additional file 1: Figure S1). This significant difference of the cuticle deposition phenotype was in line with expectations that the tissue samples obtained in present study could be used for subsequent analysis.

\section{Analysis of uterus Transcriptomic data of GC and PC group}

Seven and four biological replicate samples of uterus from GC and PC group hens during cuticle formation were analysed. A total of 590,111,516 clean reads were generated from the eleven libraries of GC and PC group (Additional file 2: Table S1). The reads feature summary indicated that the percentage of reads mapped to Gallus gallus genome was $\geq 85 \%$ (Additional file 3: Table S2). Differential gene expression analysis showed 53 differentially expressed genes (DEGs) (with 26 genes $\| \log _{2}$ fold change| $>1$ ) between the GC and PC group during cuticle formation. Among the 53 DEGs, there were 25 upregulated and 28 down-regulated genes at the PC group relative to the GC group. A full list of the 53 DEGs was shown in Table 1.

The heatmap of the 53 DEGs between GC and PC group was plotted and the pattern of expression for the 53 DEGs was visualised in Fig. 1, showing there were significant differences in the expression patterns of the 53 DEGs between GC and PC group. 
Table 1

DEGs of PC vs GC hen uterus during cuticle deposition from the transcriptomic analysis ${ }^{1}$

\begin{tabular}{|c|c|c|c|}
\hline Gene ID & Gene name & padj & $\log _{2}$ FoldChange \\
\hline MSTRG.9297 & LOC112532778 & 0.000107 & -3.38665 \\
\hline MSTRG.4468 & LOC112532092 & 0.012042 & -2.55302 \\
\hline MSTRG.19172 & novel.522 & 0.006783 & -2.46577 \\
\hline MSTRG.14500 & XLOC_018691 & 0.031623 & -2.25265 \\
\hline MSTRG.374243 & WNT2B & 0.006028 & -1.51444 \\
\hline MSTRG.15111 & LOC107054937 & 0.031252 & -1.34327 \\
\hline MSTRG.6687 & XLOC_008333 & 0.041516 & -1.28973 \\
\hline MSTRG.1320 & LOC112530330 & 0.047795 & -1.26421 \\
\hline MSTRG.7221 & LOC112532581 & 0.031623 & -1.2446 \\
\hline MSTRG.10347 & LOC107054090 & 0.005377 & -1.1694 \\
\hline MSTRG.11839 & LOC112533379 & 0.007998 & -1.07028 \\
\hline MSTRG.492 & LOC112533329 & 0.047795 & -0.97969 \\
\hline MSTRG.2992 & ABCB5 & 0.013734 & -0.9499 \\
\hline MSTRG.12238 & XLOC_015835 & 0.00254 & -0.83726 \\
\hline MSTRG.15139 & C1orf167 & 0.019222 & -0.83628 \\
\hline MSTRG.2723 & RNF32 & 0.031623 & -0.59485 \\
\hline MSTRG.12443 & LOC107054608 & 0.030626 & -0.55132 \\
\hline MSTRG.2160 & RCBTB1 & 0.031623 & -0.52116 \\
\hline MSTRG.8764 & LOC112532722 & 0.007866 & $-2.24 \mathrm{E}-05$ \\
\hline MSTRG.8709 & LOC112532731 & 0.041516 & $-1.71 \mathrm{E}-05$ \\
\hline MSTRG.6076 & SLC25A43 & 0.027852 & $-1.66 \mathrm{E}-05$ \\
\hline MSTRG.2635 & OBSCN & 0.041516 & $-1.41 \mathrm{E}-05$ \\
\hline MSTRG.4968 & LOC112532084 & 0.005377 & $-1.26 \mathrm{E}-05$ \\
\hline MSTRG.5952 & LOC112532329 & 0.031623 & $-1.50 \mathrm{E}-06$ \\
\hline MSTRG.12943 & RAD9B & 0.037819 & $-1.31 \mathrm{E}-06$ \\
\hline
\end{tabular}




\begin{tabular}{|c|c|c|c|}
\hline Gene ID & Gene name & padj & $\log _{2}$ FoldChange \\
\hline MSTRG.1636 & LOC112532721 & 0.01454 & $-1.24 \mathrm{E}-06$ \\
\hline MSTRG.8539 & XLOC_011557 & 6.01E-09 & $-2.64 \mathrm{E}-07$ \\
\hline MSTRG.7568 & LOC112532547 & 0.043812 & 7.44E-06 \\
\hline MSTRG.18849 & LOC101747670 & 0.021437 & 0.394261 \\
\hline MSTRG.11340 & PLCG2 & 0.009689 & 0.477929 \\
\hline MSTRG.7243 & ADM & 0.021437 & 0.660846 \\
\hline MSTRG.2552 & TAF10 & 0.041516 & 0.667103 \\
\hline MSTRG.13459 & PTGDS & 0.006028 & 0.728479 \\
\hline MSTRG.4035 & BAALC & 0.031252 & 0.76145 \\
\hline MSTRG.10742 & BCL2L10 & 0.02381 & 0.805203 \\
\hline MSTRG.430 & LOC101752108 & 0.002939 & 0.866194 \\
\hline MSTRG.17498 & PRLR & 0.000107 & 0.90763 \\
\hline MSTRG.14751 & ID1 & 0.006641 & 0.939962 \\
\hline MSTRG.16737 & TNS4 & 0.049612 & 1.06834 \\
\hline MSTRG.16730 & LOC112530344 & 0.00254 & 1.133301 \\
\hline MSTRG.8092 & XLOC_010789 & 0.009494 & 1.161744 \\
\hline MSTRG.5903 & FGF13 & 0.041516 & 1.167194 \\
\hline MSTRG.4978 & LRP11 & 0.016463 & 1.19355 \\
\hline MSTRG.12672 & LOC101749583 & 0.000618 & 1.21108 \\
\hline MSTRG.8621 & INA & 0.016688 & 1.484377 \\
\hline MSTRG.4238 & LOC107050437 & 0.043077 & 1.577259 \\
\hline MSTRG.11542 & TCTA & 0.000501 & 1.614429 \\
\hline MSTRG.2443 & THRSPB & 0.036456 & 1.677864 \\
\hline MSTRG.2098 & novel.32 & 0.004284 & 1.780021 \\
\hline MSTRG.11804 & novel.277 & 0.007203 & 1.802508 \\
\hline MSTRG.4206 & ARC & 0.036456 & 1.943186 \\
\hline MSTRG.10115 & NEU4 & 0.007866 & 2.080434 \\
\hline
\end{tabular}




\begin{tabular}{|lrll|}
\hline Gene ID & Gene name & padj & $\log _{2}$ FoldChange \\
\hline MSTRG.5983 & LOC100858332 & 0.000273 & 2.450145 \\
\hline 1 GC, good cuticle; PC, poor cuticle. & & \\
\hline
\end{tabular}

\section{GO functional annotation and pathway enrichment analysis of the DEGs between GC and PC group}

Functional enrichment of Gene Ontology (GO) terms and Kyoto Encyclopedia of Genes and Genomes (KEGG) pathway analysis of the 53 DEGs showed that there was no significant enriched category of GO functional annotation or KEGG pathway when subject to analysis by the DAVID Functional Annotation Tool. This may be due to the small amount of DEGs as only functions of 32 genes from the DEGs are known in the DAVID database.

\section{Verification of gene expression differences by quantitative real-time PCR (qPCR) analysis}

To validate the transcriptomics results, the relative expression of four genes [ADM (Adrenomedullin), PLCG2 (Phospholipase $\mathrm{C}$ gamma 2), PRLR (Prolactin receptor) and PTGDS (Prostaglandin D2 synthase)] to GAPDH were determined in GC and PC group by qPCR on the basis of their known or potential influence on the hen uterus functions during cuticle secretion. The four genes were all up-regulated in PC group relative to GC group (Table 1). The qPCR results showed a highly similar expression pattern compared with the RNA-Seq analysis for the genes being validated though there was slight difference in the magnitude of changes in gene expression analyzed by RNA-Seq and qPCR (Table 1; Fig. 2). The qPCR results suggested that the RNA-Seq data obtained in present study provided a good reference for the study of gene expression differences in the uterus of GC and PC group during cuticle formation.

\section{Proteomic analysis of uterus of GC and PC group}

TMT labeling based proteomic analysis of uterus samples of GC and PC group hens ( $n=4$ and 3 , respectively) during cuticle formation was further performed to identify differentially expressed proteins (DEPs). The peptide detection results of the TMT sequencing showed the length of the peptides is in a partial normal distribution with a mean value of 11 , and the main length is between $8-13$, which is reasonable for subsquent proteomic analysis. The proteomic analysis showed no DEPs were detected between the uterus samples from GC and PC group hens.

\section{Laying interval, laying performance and serum hormone levels of GC and PC group hens}

In order to further verify the results above and explore factors that affect cuticle deposition, laying interval between two consecutive ovipositions, laying performance during the twenty-seven days and 
concentrations of two serum hormones related to the RNA-Seq and qPCR results were determined in another larger White Leghorn laying hen flock. Significant differences were found in the laying interval and laying performance between GC and PC group that the GC group hens had a longer laying interval and better laying performance compared to those of PC group $(P<0.05)$ (Fig. 3, Table 2). The concentrations of prostaglandin D2 and oxytocin of PC group hen serum at $1 \mathrm{~h}$ before oviposition were higher than those of GC group, which were consistent with the RNA-Seq and qPCR results, and then the concentrations of the two hormones decreased after oviposition, but the statistical differences were not significant $(P>0.05)$ (Fig. 4).

Table 2

The laying performance during the 27-days of GC and PC group hens ${ }^{1}$

\begin{tabular}{|lll|}
\hline Traits & GC & PC \\
\hline $\mathrm{n}$ & 60 & 60 \\
\hline $\mathrm{a}^{2}$ & $38.14 \pm 4.93^{\mathrm{a}}$ & $4.28 \pm 1.68^{\mathrm{b}}$ \\
\hline Total laying days & $20.67 \pm 2.58^{\mathrm{a}}$ & $18.48 \pm 2.46^{\mathrm{b}}$ \\
\hline Total sequences & $6.02 \pm 1.31$ & $6.48 \pm 1.45$ \\
\hline Mean sequence length (days) & $3.49 \pm 1.13^{\mathrm{a}}$ & $3.06 \pm 1.05^{\mathrm{b}}$ \\
\hline Intersequence pause length (days) & $1.09 \pm 0.26^{\mathrm{b}}$ & $1.54 \pm 0.58^{\mathrm{a}}$ \\
\hline a,b Means within a row that do not share a common superscript differ significantly $(P<0.05)$. \\
\hline 1 GC, good cuticle; PC, poor cuticle. & & \\
\hline 2 $\mathrm{a}$, cuticle opacity (\%), measured in the seven-laying-days of the 28-week-old hen flock. \\
\hline
\end{tabular}

\section{Egg quality between GC and PC group hens}

Egg quality between GC and PC group hens were further measured to investigate possible reasons for the differences in laying interval and laying performance between the two groups. The results of egg quality indicated that there were significant differences in eggshell thickness (EST), eggshell strength (ESS) and eggshell weight between $\mathrm{GC}$ and $\mathrm{PC}$ group hens $(P<0.05)$, and other egg quality traits were not significantly different, suggesting the differences between GC and PC eggs were mainly reflected in the eggshell quality (Table 3). Observations and measurements of the eggshell ultrastructure by scanning electron microscope (SEM) also visually showed the huge difference in the cuticle phenotype of GC and PC group hens (Fig. 5). Further, the thicker EST of GC group was largely derived from the increase in thickness of the effective layer (including the cuticle layer) $(P<0.05)$ (Fig. 5; Table 4). 
Table 3

Egg quality and eggshell quality between GC and PC eggs ${ }^{1}$

\begin{tabular}{|lll|}
\hline Traits & GC & PC \\
\hline $\mathrm{n}$ & 30 & 30 \\
\hline $\mathrm{a}^{2}$ & $40.26 \pm 5.24^{\mathrm{a}}$ & $13.0 \pm 4.03^{\mathrm{b}}$ \\
\hline Eggshell thickness $(\mu \mathrm{m})^{3}$ & $368.68 \pm 23.95^{\mathrm{a}}$ & $342.95 \pm 41.28^{\mathrm{b}}$ \\
\hline Eggshell weight $(\mathrm{g})$ & $5.88 \pm 0.46^{\mathrm{a}}$ & $5.53 \pm 0.75^{\mathrm{b}}$ \\
\hline Eggshell strength $\left(\mathrm{kg} / \mathrm{cm}^{2}\right)$ & $3.65 \pm 0.78^{\mathrm{a}}$ & $3.02 \pm 0.74^{\mathrm{b}}$ \\
\hline Egg weight $(\mathrm{g})$ & $54.60 \pm 3.62$ & $55.01 \pm 3.10$ \\
\hline Egg yolk weight $(\mathrm{g})$ & $16.07 \pm 3.30$ & $16.60 \pm 1.34$ \\
\hline Egg albumen height $(\mathrm{mm})$ & $6.43 \pm 1.16$ & $6.33 \pm 1.77$ \\
\hline Egg yolk color & $9.32 \pm 0.59$ & $9.31 \pm 0.78$ \\
\hline Haugh unit & $81.15 \pm 7.75$ & $79.22 \pm 12.30$ \\
\hline Egg shape index & $1.35 \pm 0.08$ & $1.35 \pm 0.06$ \\
\hline a,b Means within a row that do not share a common superscript differ significantly $(P<0.05)$. \\
\hline 1 GC, good cuticle; PC, poor cuticle. & & \\
\hline${ }^{2} \mathrm{a}$, cuticle opacity (\%). & & \\
\hline${ }^{3}$ Eggshell thickness without eggshell membranes. & \\
\hline
\end{tabular}


Table 4

Eggshell ultrastructure thickness of GC and PC eggs ${ }^{1}$

\begin{tabular}{|lll|}
\hline Traits & GC & PC \\
\hline $\mathrm{n}$ & 30 & 30 \\
\hline $\mathrm{a}^{2}$ & $50.55 \pm 9.53^{\mathrm{a}}$ & $0.29 \pm 2.15^{\mathrm{b}}$ \\
\hline Cuticle thickness $(\mu \mathrm{m})$ & $8.18 \pm 0.83^{\mathrm{a}}$ & $1.52 \pm 0.21^{\mathrm{b}}$ \\
\hline Effective layer thickness $(\mu \mathrm{m})^{3}$ & $281.09 \pm 24.57^{\mathrm{a}}$ & $254.48 \pm 32.18^{\mathrm{b}}$ \\
\hline Mammillary layer thickness $(\mu \mathrm{m})$ & $66.04 \pm 14.97$ & $60.70 \pm 14.11$ \\
\hline Eggshell thickness $(\mu \mathrm{m})$ & $352.01 \pm 23.04^{\mathrm{a}}$ & $316.20 \pm 30.58^{\mathrm{b}}$ \\
\hline a,b Means within a row that do not share a common superscript differ significantly $(P<0.05)$. \\
\hline${ }^{1} \mathrm{GC}$, good cuticle; PC, poor cuticle. & \\
\hline${ }^{2} \mathrm{a}$, cuticle opacity $(\%)$. & \\
\hline${ }^{3}$ Effective layer thickness is the combined thickness of the palisade, vertical crystal and cuticle layer. \\
\hline
\end{tabular}

\section{Discussion}

Egg formation in avian reproductive tract is strictly regulated by the hormons and gene expression [20, 22], and the cuticle layer is the last process of egg formation in most avian species [12], however, the genetic regulation of cuticle deposition is still poorly understood. Considering the importance of eggshell cuticle and the genetic improvement of this trait in poultry production, present study were conducted by analyzing the DEGs and DEPs of the uterus between GC and PC group hens to elucidate potential genes and networks that regulate cuticle deposition. Besides, results of qPCR and a series of phenotypic measurements validated the RNA-Seq data. The current work not only picturised the differential expression profile of the uterus of GC vs PC group hens during eggshell cuticle formation, but also revealed important genes affecting cuticle deposition.

DEGs obtained in the transcriptome analysis of the uterus of GC and PC group hens during cuticle formation ( $1 \mathrm{~h}$ before oviposition) are very likely to be genes that regulate cuticle formation. Based on the results of DEGs, multiple genes (such as PTGDS, PLCG2, ADM and PRLR) related to uterine functions and reproductive hormones were found. The qPCR results further validated the DEGs that the gene expression levels of PTGDS, PLCG2, ADM and PRLR in the uterus of PC group hens were all higher than those of GC group, suggesting their vital roles during cuticle formation.

PTGDS is one of the prostaglandin synthases [31], and it's also an important catalytic enzyme for the synthesis of prostaglandins $[32,33]$. Studies on humans and mice have demonstrated that 
prostaglandins are involved in sleep induction [34, 35], intake behavior [36] and reproduction processes [37]. Prostaglandins are mostly used to induce parturition in clinical practice. In poultry, injection of prostaglandins can be used to control the uterine contractility and then induce premature oviposition [12, $38,39]$.

PLCG2, which is a type of the phospholipase C (PLC), is an important mediator of oxytocin to regulate uterine contractions [40]. One of the important functions of oxytocin is to stimulate the contractions of myometrium during parturition in mammals and birds [41-43]. Oxytocin directly binds to the oxytocin receptor, which is subsquent activated and coupled to the G protein, to activate the PLC on the intracellular membranes, activating the influx of calcium and finally regulating contractions of the myometrium by voltage [40,43-46]. In addition, another function of oxytocin is to increase the synthesis of prostaglandin by stimulating the activity of endometrial prostaglandin synthetase, and then the synergetic effect of prostaglandin and oxytocin enhances the activity of myometrium, thereby inducing labor or oviposition [44-51].

ADM is a peptide with several functions, including vasodilation, regulation of hormone secretion, promotion of angiogenesis, regulation of follicular growth and luteinization of ovarian follicles [52]. In the labor activities of human and mice, ADM in the uterus binds to the receptor and enters the cell to participate in the relaxation of myometrium [43]. Though the relaxation function of ADM is opposite to the contractile effects of oxytocin and prostaglandin in myometrium, ADM could cooperate with oxytocin and prostaglandin to participate in the rhythmical contraction and relaxation of the myometrium $[43,48$, $53,54]$.

Prolactin (PRL), secreted from the anterior pituitary, plays a series of roles in osmoregulation, corpus luteum formation and maintenance of broody behaviour in laying hens, and its receptor, PRLR, plays an important role in the PRL signal transduction cascade and cell growth and differentiation [55]. The $P L R$ and $P R L R$ genes are expressed in many tissues including the hypothalamus, ovary and oviduct [56,57], and mediate the formation of egg quality [58]. PRL is generally considered to be a key factor in the onset and maintenance of broody behaviour in birds, and it has been well established that the elevated plasma PRL inhibits gonadotropin release, ovum development and ovulation, resulting poor laying performance and even complete cessation of egg production in laying hens [59-62]. Transcriptome studies have also revealed PRL is associated with egg production performance in chicken hypothalamic-pituitary-ovarian axis $[63,64]$. Therefore, the significant difference in eggshell quality (EST, ESS, eggshell weight, and cuticle opacity) and egg production performance between GC and PC group hens may be related to the different expression patterns of PRLR gene in the uterus. Previous study has shown the inhibitory effects of excessive PRL on eggshell formation [62]. Gonadotropin-releasing hormone (GnRH) is considered to be an important factor in promoting the cuticle deposition [12], however, the elevation of PRL can significantly inhibit the secretion and function of GnRH [55]. Besides, environmental stressors would negatively affect the cuticle deposition with an increased PRL secretion [12, 65]. Follicle maturation, ovulation and egg formation are physiological events involving multiple organizations and processes, thus, the physiological difference of the hen uterus alone seems to be insufficient to explain its impact on 
egg production performance. Considering the inhibitory effects of PRL on eggshell formation and egg production, it's speculated that the PRL level and PRLR gene expression level in the hypothalamopituitary-gonadal-oviduct axis are higher in the PC group hens. However, the effects of PRL and PRLR on hen uterine function are still unclear.

Summarizing the functions of PLCG2, PTGDS, ADM and PRLR expressed in the uterus, their express patterns in the uterus regulate the muscular activities and secretion function, which may lead to the difference in egg-laying rhythm between GC and PC group hens. The relatively high expressions of PLCG2, PTGDS and ADM genes could increase the frequency and intensity of contraction and relaxation activities of the myometrium that might negatively affect uterine functions and eventually facilitate oviposition. Combined the results of RNA-seq and qPCR analysis, in other words, hens with good cuticle deposition are more likely to oviposition accompanied by a extended duration for the egg staying in the uterus. This point of view was confirmed by the observations during the experiment, that is, in order to more accurately collect the uterine tissue samples during the cuticle secretion period, in the process of estimating the oviposition time of the hens, it was found that the laying interval between two consecutive ovipositions of the GC group was longer. The difference in laying interval between GC and PC group hens was further confirmed by the larger experimental flock, namely the laying interval between two consecutive ovipositions of GC group hens was significantly longer than that of PC group by $0.7 \mathrm{~h}$ (Fig. 3). At the same time, the concentrations of prostaglandin D2 and oxytocin of PC hen serums at $1 \mathrm{~h}$ before oviposition were higher than those of GC group hens though the statistical differences were not significant $(P>0.05)$. There was also a tendency that the concentrations of prostaglandin D2 and oxytocin of hen serum after oviposition were decreased, implying their important role in regulating uterine functions. The statistically insignificant differences may be due to the large difference in physiological status between individuals and the short biological half-life of oxytocin and prostaglandin [66, 67], however, the serum hormone levels was consistent with the RNA-Seq and qPCR results. The cuticle only begins to secrete $2-1.5 \mathrm{~h}$ before oviposition, and the secretion stops after the egg enters the vagina, so the secretion duration is relatively short [12]. The results above indicated that during the cuticle secretion period in the uterus, the frequency and intensity of myometrium contraction and relaxation in GC group hens might be lower than that of PC group hens, which might extend the duration of the cuticle formation, and then lead to the good cuticle quality.

There were no DEPs between the uterus samples of GC vs PC group hens analyzed by the proteomic analysis, implying there was no significant difference in the protein composition and content to a large extent. Alternative hypothesis is that undetected DEPs may be due to the extensive posttranslational modification regulation in the biological process $[68,69]$. On the other hand, the extremely short half-life of the hormones (e.g. oxytocin) may be the reason why the DEPs were not found $[66,67,70]$. The expression characteristics of the transcriptome and proteome between GC and PC group are highly similar (53 DEGs and no DEPs), suggesting that the biological processes of cuticle formation of the two groups may be the same, but mainly the difference in the duration of cuticle secretion. 
Therefore, the duration of cuticle secretion in the uterus may be a major factor affecting cuticle quality. However, from ovulation to oviposition, it takes about 24 hours for the formation of a complete egg in chicken $[10,20]$. A complete egg includes egg yolk, egg white, eggshell membranes, calcified eggshell and cuticle formation. The forming egg stays in different segments of the oviduct (i.e., infundibulum, magnum, isthmus and uterus) for different duration, and the egg remains in the uterus for the longest period during shell and cuticle formation, for a duration over $18 \mathrm{~h}$ in laying hens $[10,20,71]$. Thus, it is not clear whether the longer laying interval in GC group hens is entirely derived from the extended cuticle secretion time. The egg quality measurement results showed that there were no significantly differences in the egg weight, yolk weight, yolk color, albumen height, haugh unit and egg shape index between GC and PC group. Surprisingly, the eggshell quality (EST, ESS, eggshell weight, and cuticle opacity) of GC group were significantly increased compared with PC group, further suggesting that the the longer laying interval in GC group was mainly due to the extended formation duration of the eggshell in the uterus. The eggshell comprises four morphologically distinct layers that are formed sequentially, starting with the innermost mammillary layer, followed by the palisade, the vertical crystal layer and the cuticle [10]. Eggshell ultrastructure of GC and PC group eggs by SEM shows the significantly increased EST of GC group is largely due to the increase in the thickness of the effective layer (palisade, vertical crystal layer and cuticle), demonstrating the extended laying interval of GC group hens both positively affects the calcified shell and cuticle formation. EST and ESS traits are highly correlated in phenotype and genetic $[58,72]$. The effective layer thickness is the major ultrastructural characteristic compromising ESS [73]. Eggshell formation takes place in the uterus over an $18 \mathrm{~h}$ period and the laying interval between ovipositions were positively correlated with the duration of eggshell formation, eggshell deposition rate and eggshell quality, and in detail, a difference of 0.7 hours between egg laying intervals could significantly affect eggshell weight and eggshell deposition rate by about 30\% [71]. Consequently, in present study, the prolonged laying interval by $0.7 \mathrm{~h}$ of GC group hens could explain the significant increase in the effective layer and cuticle layer thickness.

It is hypothesized that extended duration of eggshell formation and better secretion function of the uterus simultaneously promote the formation of good eggshell and cuticle quality. The heritability of cuticle trait is $0.27-0.40[8,19,74]$. Previous studies have also shown the cuticle quality is weakly positive correlated with the EST/ESS (< 0.2 in phenotypic and genetic correlation) in several commercial laying hen flocks (brown-shelled, white-shelled and tinted-shelled) $[17,74]$. The results of present study directly prove that eggs with good or poor cuticle generally embody thicker or thinner EST that the top (good) and tail (poor) of the cuticle deposition distribution amplified the difference in eggshell quality traits. It's suggested that eggshell calcification is precisely regulated by the interaction processes between mineral and organic precursors under gene expressions, including transcellular and paracellular transport of minerals and the secretion of different matrix proteins $[28,75-78]$. The processes establish the eggshell texture and ultrastructure, and then influence eggshell quality traits [78-80]. Eggshell matrix proteins (e.g., ovocleidin17 , ovocleidin-116, ovocalyxin-32, ovocalyxin- 21 and ovalbumin) present in both the calcified eggshell and the cuticle, and eggshell matrix proteins constitutes the main components of the cuticle [78, 81, 82]. Previous transcriptomic study in the uterus of laying hens that produce eggs with good or poor eggshell 
quality (EST/ESS) demonstrated the most of identified DEGs were involved in eggshell calcification (ion transport) and cuticularization (matrix proteins) pathways [83]. It was found that the expression of FGF13 (fibroblast growth factor 13) is up-regulated in the uterus of PC group as compared to GC group (Table 1). FGF13 is a well-known growth factor belonging to the $F G F$ family and is the modulator voltage-gated $\mathrm{Na}^{+}$, $\mathrm{Ca}^{2+}$ and $\mathrm{K}^{+}$channels $[84,85]$. FGF13 could increase voltage-gated $\mathrm{Na}^{+}$and $\mathrm{Ca}^{2+}$ channel availability [84, 86], and it's suspect that the up-regulated FGF13 also increased the uterine contractility. Simultaneously, there is also a significant association between ovocleidin-116, ovocalyxin-32 and ovalbumin genes with EST and cuticle deposition $[8,29]$. Thus, the poor eggshell and cuticle qualities are likely mediated by dysregulation of both ion channels and matrix proteins during eggshell formation, which may also caused by the high expressions of PTGDS, PLCG2, ADM and PRLR genes that the uterine functions are negatively affected by the muscular activities based on the voltage-gated ion channels. To put it simply, during the eggshell formation period, the uterine secretion environment of GC hens is more stable, which ensures the duration for eggshell formation and thus the eggshell and cuticle quality.

The difference in eggshell quality and laying interval between GC and GC group may result from the difference in the uterine biological clock rhythm. Generally, hens lay eggs at intervals precisely controlled by the hormonal secretion and gene expression of the hypothalamo-pituitary-gonadal-oviduct axis. In laying hens, during the maturation of follicular, ovulation, and formation of the egg, the coincidence of the different physiological processes in time demonstrates that the laying rhythm is regulated by the endogenous circadian clock [21]. The circadian clock is a major regulator of a wide range of behavioral and physiological processes including metabolism, food intake, sleep, body temperature, endocrine, immune, reproductive systems and orchestrates rhythmic gene expression in diverse organisms to maintain consistency between body metabolism and the external environment [87, 88]. In chickens, clock genes include PER, CRY, BMAL and CLOCK genes, which are expressed in several organisms including the central circadian clock (the pineal, the retina and the hypothalamus) and the peripheral circadian clock (almost all tissues throughout the body), is essential for synchronizing gene expression of key metabolic pathways to coordinate the time course of physiological and behavioral processes [89, 90]. In present study, the difference in laying interval of GC and PC group hens is mainly due to the difference in the calcified eggshell and cuticle formation period in the uterus, showing the uterine clock may be a main factor affecting the cuticle deposition as the eggshell formation is directly regulated by the uterine clock [91]. This inference is supported by earlier research, that is, clock gene expression in the uterus during shell formation may be responsible for controlling the cuticle deposition, and PER2, CRY2, CRY1, CLOCK and $B M A L 1$ genes were differentially expressed when cuticle deposition was prevented by arginine vasotocin [30]. The contractile responses of the uterus to prostaglandins and arginine vasotocin play an important role in inducing oviposition [92]. Arginine vasotocin and prostaglandin is thought to mediate the brain to ovary signalling of oviposition timing being involved in cuticle deposition, and the premature oviposition induced by arginine vasotocin and prostaglandin significantly reduce the EST and cuticle deposition [12], which supports the results of present study. The transcriptome results of present study also captured genes that regulate uterine muscular activities such as PLCG2, PTGDS, and ADM, however, clock genes and proteins were not detected in the transcriptome and proteome analysis, which could be

Page 15/38 
due to the half-life of clock genes and proteins that would not be apparent in the transcriptome and proteome $[30,93]$. Therefore, genes related to uterine timing mechanism and muscular events constitute the components of cuticle deposition regulation, but the regulatory networks need further research.

\section{Conclusions}

By analyzing the transcriptome and proteome of the uterus from hens that produced eggs with good or poor cuticle deposition, PTGDS, PLCG2, ADM and PRLR genes were discovered and might play crucial roles in cuticle deposition by affecting uterine secretion rhythm and function. Compared with the PC hens, the relatively low expression of these genes in the uterus ensured the eggshell and cuticle formation duration, and lead to the good eggshell and cuticle quality of the GC hens. Moreover, eggshell quality and laying performance of hens that produce eggs with good cuticle are better, implying the importance of genetic selection to the cuticle trait in laying hens. This study also hints at the relationship between the cuticle formation and the endogenous circadian clock, which might provide a basis for subsequent poultry production improving the cuticle quality by improving exogenous daily inputs (e.g., photoperiod, nutrition).

\section{Methods}

\section{Ethical statement}

All the experimental procedures were conducted in accordance with the Guidelines for Experimental Animals established by the Animal Care and Use Committee of China Agricultural University (permit number: AW08059102-1). Animal studies were reported in compliance with the ARRIVE guidelines [94].

\section{Experimental design}

One 28-week-old White Leghorn laying hen flocks $(n=208)$ were used in present study for omics analysis and then another 28-week-old White Leghorn laying hen flocks $(n=574)$ were choosed for further verification tests. There was no genetic selection for the cuticle trait of the two flocks. Hens that stably produced eggs with good and poor cuticle (GC and PC, the top and tail of the cuticle deposition distribution) were obtained by evaluating the cuticle quality. According to the ARRIVE guidelines [94], in the preliminary experiment of present study, the differences of the top and tail of the cuticle deposition distribution of the two flocks were significant large to obtain enough GC and PC hens for the experiments (GC group hens had a strong ability for cuticle deposition whilst the PC groups hens had almost no secretion of cuticle). Transcriptomic, proteomic and qPCR analysis of GC and PC hen uterus tissues during cuticle deposition were designed for identifying genes involved with eggshell cuticle deposition. Subsequently, phenotypic measurements (cuticle opacity, laying interval, laying performance, serum hormone level, egg quality) of GC and PC group hens were carried out to further verify the results above.

\section{Animals and uterine tissue collection}


Two hundred and eight White Leghorn hens at 28-week-old were selected form the National Poultry Testing Center, China Agricultural University. All hens were caged individually under standard conditions with a photoperiod of $16 \mathrm{~L}: 8 \mathrm{D}$, and the diet and water were provided ad libitum.

To obtain individuals that stably produced eggs with good or poor cuticle (GC or PC) for subsequent sampling, the eggs were collected for 2 weeks to measure the cuticle quality within $24 \mathrm{~h}$ after oviposition. The cuticle quality evaluation was conducted according to the staining method proposed by Chen et al. previously [17]. Briefly, the cuticle opacity (a value) was measured based on differences in cuticle staining before and after staining with a dye solution of MST cuticle blue (MS Technologies Ltd, UK) using a spectrophotometer (CM-2600d; Konica Minolta, Japan) with the XYZ color space system. A higher a value represents to more cuticle deposition, that is better cuticle quality. Each egg was measured at 3 points: the large end, equator, and small end. Cuticle quality per egg was determined from the mean value of these points and at least 8 eggs were collected for cuticle quality measurement per hen.

Oviposition time of each hen was accurately recorded from the second week of egg collection. Then the oviposition time of the GC and PC group hens were estimated and the hens were euthanized by T-61 intravenously $(0.4 \mathrm{ml} / \mathrm{kg}) 1 \mathrm{~h}$ before oviposition (the period for cuticle secretion) on the fifteenth day. The uterus was aseptically retracted through an abdominal incision and a small incision was then made in the centre of the uterus, and the egg in the uterus was removed for staining by MST cuticle blue after 30 min to determine whether the cuticle is secreted in the uterus during sampling. Two approximately 500 $\mathrm{mg}$ sample tissues was collected from the centre of the uterus and transferred directly to RNAlater (Sigma-Aldrich, Shanghai, China), quickly frozen in liquid nitrogen and stored at $-85^{\circ} \mathrm{C}$ prior to total RNA extraction.

\section{Transcriptomic analysis}

Total RNA was extracted from frozen uterus tissue sample using TRIzol reagent (TransGen Biotech, Beijing, China). The quality and quantity of RNA were evaluated by $1 \%$ agarose gels, NanoDrop 2000 spectrophotometer (Thermo Fisher Scientific, Wilmington, DE, USA), respectively. The RNA integrity was assessed using the RNA Nano 6000 Assay Kit of the Bioanalyzer 2100 system (Agilent Technologies, CA, USA). Three $\mu \mathrm{g}$ RNA per sample was prepared to generate individual bar-coded sequencing libraries using NEBNext ${ }^{\circledR}$ UltraTM RNA Library Prep Kit for Illumina ${ }^{\circledR}$ (NEB, USA) following manufacturer's recommendations. Sequencing of these libraries was performed on an Illumina HiSeq 4000 sequencing system (Illumina, San Diego, CA, USA) using the 150-bp pair-end sequencing strategy, following the manufacturer's instructions.

Raw data was quality controlled using the FastQC package (Babraham bioinformatics, Cambridgeshire, England). Clean reads were obtained by removing reads containing adapter, reads containing ploy- $\mathrm{N}$, empty reads and low quality reads from raw data. Trimmed reads were mapped on the reference chicken genome Gallus_gallus_ncbi_GCF_000002315.6_GRCg6a (https://www.ncbi.nlm.nih.gov/assembly/GCF_000002315.6) using HiSAT2.0 [95, 96]. The clean reads of 
each sample were assembled and finally merged to a transcriptome using Stringtie (http://ccb.jhu.edu/software/stringtie/) [95] with Ensembl Gallus gallus.v92 as the reference. Expression levels of the transcripts were quantified as RPKM (reads per kilobase per million) for gene expression analysis.

DEGs were identified using DESeq2 [97] according to the cretiera of adjusted $P$-value $<0.05$. Ensembl gene IDs from each group were uploaded to the DAVID Functional Annotation Tool and analysed for gene ontology (GO) and Kyoto Encyclopaedia of Genes and Genomes (KEGG) enrichment [98, 99]. The transcriptome data (raw mRNA-seq reads) have been deposited with the National Center for Biotechnology Information (NCBI) Sequence Read Archive (SRA) database under accession number PRJNA664894 (https://www.ncbi.nlm.nih.gov/sra/PRJNA664894).

\section{Proteomic analysis}

Each frozen sample (50 mg) from GC and PC group hens ( $n=4$ and 3, respectively) was ground in liquid nitrogen and suspended in lysis buffer consisting of $8 \mathrm{M}$ urea (Sigma Aldrich, MO, USA), $10 \mathrm{mM}$ dithiothreitol (DTT), and proteinase inhibitors (Merck Millipore, MA, USA). The digest was centrifuged at $12,000 \times \mathrm{g}$ for $20 \mathrm{~min}$ at $4{ }^{\circ} \mathrm{C}$, and the supernatant was collected. The concentration was determined with a BCA kit (Thermo Fisher Scientific, Wilmington, DE, USA) according to the manufacturer's protocols. After trypsin digestion, the peptides were desalted with buffer $\mathrm{A}$ [10 $\mathrm{mM} \mathrm{KH}_{2} \mathrm{PO}_{4}$ in $25 \%$ acetonitrile (ACN), pH 3.0] and buffer $B\left(10 \mathrm{mM} \mathrm{KH}_{2} \mathrm{PO}_{4}, 500 \mathrm{mM} \mathrm{KCl}\right.$, in $\left.25 \% \mathrm{ACN}, \mathrm{pH} 3.0\right)$ at a low rate of $1,000 \mu \mathrm{L} / \mathrm{min}$, lyophilised in a centrifugal speed vacuum concentrator, reconstituted in $0.5 \mathrm{M}$ TEAB and processed according to the manufacturer's instructions for the TMT kit (Thermo Fischer Scientific, MA, USA). The tryptic peptides were separated by high-pH reverse-phase HPLC using an Agilent 300 Extend C 18 column ( $5 \mu \mathrm{m}$ particle size, $4.6 \mathrm{~mm}$ inner diameter, $250 \mathrm{~mm}$ length), dissolved in $0.1 \%$ formic acid (Sigma Aldrich, MO, USA) and fractionated using EASY-Nano-LC 1000 ultra-high performance liquid phase system. Finally, fractionated peptides were exposed to an NSI source followed by tandem mass spectrometry (MS/MS) with a Q Exactive HF-X spectrometer (Thermo Fischer Scientific, MA, USA) coupled online to the UPLC system.

The MS/MS data were searched against the Gallus gallus database (http://www.uniprot.org/proteomes/UP000000539, chicken proteome ID: UP000000539) for peptide identification and quantification using the Maxquant search engine (v.1.6.6.0). All proteins with at least one unique peptide and false discovery rate $(F D R)<0.01$ were qualified for further quantification data analysis. Protein abundance was quantified by hi-flyer through loading (SL), internal reference scaling (IRS) and trimmed mean of M values (TMM) corrections in the Maxquant search engine system. DEPs between GC and PC group were identified using limma [100] and $P<0.05$ was used as the cut-off for significance by FDR correction.

\section{Quantitative real-time PCR (qPCR)}


Expression of mRNA was verified by qPCR with cDNA from 11 uterine tissue samples. GAPDH gene served as a housekeeping gene. Primer Primer (v. 5.0) was used with default parameters to design primers on exon-exon spans for selected genes (Additional file 4: Table S3). Total RNA was extracted from uterine tissue using TRIzol reagent as described previously. Synthesis of the cDNA was performed using a PrimeScript RT reagent kit with $1 \mu \mathrm{g}$ of the RNA pretreated with gDNA Eraser (TaKaRa, Dalian, China) following the manufacturer's instructions. The qPCR of the mRNA expression level of $A D M$, PLCG2, PRLR and PTGDS was performed using the Agilent Brilliant III Ultra-Fast SYBR Green qPCR Mix and MX3005P real time system (Agilent; Santa Clara, CA USA). The experiments were carried out in triplicate. The cycling conditions were $50^{\circ} \mathrm{C}$ for $2 \mathrm{~min}$, followed by 40 cycles at $95^{\circ} \mathrm{C}$ for $15 \mathrm{~s}$ and $60^{\circ} \mathrm{C}$ for $1 \mathrm{~min}$ by 42 cycles, and annealing and extension at $60^{\circ} \mathrm{C}$ for $15 \mathrm{~s}$. The melting curves were obtained for each sample amplified. The $2^{-\triangle \triangle C T}$ method was used [101] to quantify the relative changes in gene expression versus those of GAPDH from the qPCR experiments and $t$-test was used for the statistical analysis by $\mathrm{R}$ Language (v. 3.4.0).

\section{Verification experiments}

Five hundred and seventy four White Leghorn hens at 28-week-old were selected form the Poultry Genetic Resources and Breeding Experimental Base, College of Animal Science and Technology, China Agricultural University for subsequent verification analysis. The animal handling and housing conditions were the same as described above.

All eggs produced by this flock were collected, and cuticle opacity measurement and oviposition time recording were in accordance with the first experiment for seven successive laying days. On the sixth day, hens that stably produced eggs with good and poor cuticle quality (GC and PC) were selected and their oviposition time on the seventh day were estimated. On the seventh day, whole blood samples were collected from the brachial veins of the GC and PC group hens at $1 \mathrm{~h}$ before oviposition, and the blood samples were also collected from the $\mathrm{GC}$ hens at $0.5 \mathrm{~h}$ after oviposition (laid) $(\mathrm{n}=7)$. All the eggs were also collected after oviposition for validation by cuticle opacity measurement. The blood sample was collected only once per chicken and the cuticle quality and oviposition time were in line with expectations.

Laying interval between two consecutive ovipositions was calculated (at least 4 ovipositions per hen). Laying recording sheet during the 27 consecutive laying days from 28-week-old age was obtained to evaluate laying performance (i.e., total laying days, total sequences, mean sequence length and intersequence pause length). Concentrations of prostaglandin D2 and oxytocin of the blood serum were subsequently determined by chicken prostaglandin D2 (PGD2) and oxytocin (OT) ELISA kits (mlbio, Shanghai, China) according to the manufacturer's protocols.

After cuticle opacity measurement, other egg quality traits of GC and PC group hens $(n=30)$ including egg weight, eggshell thickness (EST, mean of the large end, equator, and small end without eggshell membranes), eggshell strength (ESS), yolk weight, albumen height, yolk colour, haugh unit and egg shape index were determined using an egg multitester (EMT-5200, robotmation, Japan), an Eggshell Strength 
Tester (EFG-0503, robotmation, Japan) and a digital display micrometer gauge (Mitutoyo, Kawasaki, Japan) following the manufacturer's instructions. Eggshell pieces (about $1 \mathrm{~cm}^{2}$ ) of the GC and PC group hens $(n=30)$ were taken around the equator of the egg and the pieces were mounted on an aluminum stub and gold sputter-coated using an EIKO IB-3 (EIKO Engineering CO., Ltd, Japan) for about 15 min. Thereafter, they were subjected to the SEM (JSM-7401, JEOL Ltd., Japan) for observations, photographing, and measurements of the eggshell cross-section ultrastructure. The eggshell crosssection ultrastructure in present study refers to eggshell thickness (EST), effective layer thickness (combined thickness of the palisade, vertical crystal and cuticle layer) and mammillary layer thickness, and the determination were consistent with previous studies [29, 102].

\section{Statistical analysis}

Statistically significant differences among descriptive statistics were determined by the Duncan's test. All statistical analysis and figure plotting were performed with the statistical software RStudio (v. 3.4.0). The results of basic descriptive statistics are shown in paragraphs and tables using the mean and standard deviation (mean $\pm S D$ ).

\section{Abbreviations}

$A D M$

Adrenomedullin; DEGs:Differentially expressed genes; DEPs:Differentially expressed proteins; EST:Eggshell thickness; ESS:Eggshell strength; ESR1:Estrogen receptor; FDR:False discovery rate; FGF13:fibroblast growth factor 13; FSIN:Food Security Information Network; GAPDH, Glyceraldehyde-3phosphate dehydrogenase; GnRH:Gonadotropin-releasing hormone; GC:good cuticle; GO:Gene Ontology; KEGG:Kyoto Encyclopaedia of Genes and Genomes; PC:poor cuticle; PLC:phospholipase C; PLCG2:Phospholipase C gamma 2; PRL:Prolactin; PRLR:Prolactin receptor; PTGDS.Prostaglandin D2 synthase; qPCR:Quantitative real-time PCR.

\section{Declarations}

\section{Acknowledgements}

The authors would like to thank the staff in the National poultry Testing Center and Poultry Genetic Resources and Breeding Experimental Base, College of Animal Science and Technology, China Agricultural University for bird care. We gratefully acknowledge our colleagues on the College of Animal Science and Technology of China Agricultural University for their assistance during the experiment.

\section{Authors' contributions}

JXZ, XC, ZXH and XZL developed the hypothesis and designed the overall experimental plan. XC, ZXH, JLS, MYH, XFS and XYL obtained the samples and measurement data. XC, ZXH and XZL participated in data analyses. JXZ, NY, GYX and JYL provide the necessary experimental resources for the development 
of this research. XC, ZXH, GYX, NY and JXZ drafted and revised this manuscript. All authors reviewed and approved the manuscript for publication.

\section{Funding}

This study was supported by the National Natural Science Foundation of China (31672408); the China Agriculture Research Systems (CARS-41); the Special Fund for Agro-scientific Research in the Public Interest (201303084); the Program for Changjiang Scholars and Innovative Research Team in University (IRT 15R62). The funders did not involve in the study design, data collection and analysis, decision to publish, or preparation of the manuscript.

\section{Availability of data and materials}

The transcriptome data (raw mRNA-seq reads) of present article data are available in the National Center for Biotechnology Information (NCBI) Sequence Read Archive (SRA) database under accession number PRJNA664894 (https://www.ncbi.nlm.nih.gov/sra/PRJNA664894).

\section{Ethics approval and consent to participate}

All the experimental procedures were conducted in accordance with the Guidelines for Experimental Animals established by the Animal Care and Use Committee of China Agricultural University (permit number: AW08059102-1).

\section{Consent for publication}

No applicable.

\section{Competing interests}

The authors declare that they have no competing interests.

\section{Author details}

${ }^{1}$ National Engineering Laboratory for Animal Breeding and MOA Key Laboratory of Animal Genetics and Breeding, College of Animal Science and Technology, China Agricultural University, Beijing, 100193, China;

${ }^{2}$ Institute of Animal Husbandry and Veterinary Medicine, Beijing Academy of Agriculture and Forestry Sciences, Beijing, 100097, China; ${ }^{3}$ Shenzhen agricultural Genome Research Institute, Chinese Academy of Agriculture Sciences, Shenzhen, 440307, China.

\section{References}

1. FSIN. The Global Report on Food Crises 2020. 2020. https://www.fsinplatform.org/sites/default/files/resources/files/GRFC_2020_ONLINE_200420.pdf. Accessed 20 Sept 2020. 
2. Mottet A, Tempio G. Global poultry production: current state and future outlook and challenges. World's Poult Sci J. 2017;73(2):1-12.

3. Gantois I, Ducatelle R, Pasmans F, Haesebrouck F, Gast R, Humphrey T, Immerseel F. Mechanisms of egg contamination by Salmonella Enteritidis: Review article. FEMS Microbiol Rev. 2009;33:718-738.

4. Baron F, Jan S, Nys Y, Bain M, Immerseel F. Egg and egg product microbiology. In: Nys Y, Bain M, Immerseel FV, editors. Improving the safety and quality of eggs and egg products Vol 1: Egg chemistry, production and consumption. Woodhead Publishing, Cambridge; 2011. p. 330-350.

5. Bain M, Zheng J, Zigler M, Whenham N, Quinlan-Pluck F, Jones A, Roberts M, Icken W, Olori V, Dunn I. Cuticle deposition improves the biosecurity of eggs through the laying cycle and can be measured on hatching eggs without compromising embryonic development. Poult Sci. 2018;98(4):1775-1784.

6. D'Alba L, Shawkey M. Mechanisms of antimicrobial defense in avian eggs. J Ornithol. 2015;156:399408.

7. Hincke M, Gautron J, Nys Y, Rodriguez-Navarro A, McKee M, Bain M, Immerseel F. The eggshell: structure and protective function. In: Nys $Y$, Bain M, Van Immerseel FV, editors. Improving the safety and quality of eggs and egg products Volume 1: Egg chemistry, production and consumption. Woodhead Publishing, Cambridge; 2011. p. 151-182.

8. Bain M, Mcdade K, Burchmore R, Law A, Wilson P, Schmutz M, Preisinger R, Dunn I. Enhancing the egg's natural defence against bacterial penetration by increasing cuticle deposition. Anim Genet. 2013;44(6):661-668.

9. D'Alba L, Jones D, Eliason C, Badawy H, Shawkey M. Antimicrobial properties of a nanostructured eggshell from a compost-nesting bird. J Exp Biol. 2014;217(Pt 7):1116-1121.

10. Hincke M, Nys Y, Gautron J, Mann K, Rodriguez-Navarro A, McKee M. The eggshell: structure, composition and mineralization. Front Biosci. 2012;17(1):1266-1280.

11. Kulshreshtha G, Rodrigueznavarro A, Sanchezrodriguez E, Diep T, Hincke MT. Cuticle and pore plug properties in the table egg. Poult Sci. 2018;97(4):1382-1390.

12. Wilson P, Suther C, Bain M, Icken W, Jones A, Quinlan-Pluck F, Olori V, Gautron J, Dunn I. Understanding avian egg cuticle formation in the oviduct; a study of its origin and deposition. Biol Reprod. 2017;97(1):39-49.

13. Kusuda S, Iwasawa A, Doi O, Ohya Y, Yoshizaki N. Diversity of the Cuticle Layer of Avian Eggshells. J Poult Sci. 2011;48(1):119-124.

14. Fecheyr-Lippens DC, Igic B, D'Alba L, Hanley D, Verdes A, Holford M, Waterhouse GIN, Grim T, Hauber ME, Shawkey MD. The cuticle modulates ultraviolet reflectance of avian eggshells. Biol Open. 2015;4(7):753-759.

15. Wellman-Labadie O, Picman J, Hincke MT. Antimicrobial activity of the Anseriform outer eggshell and cuticle. Comp Biochem Physiol. 2008;149(4):640-649.

16. Rose-Martel M, Du J, Hincke MT. Proteomic analysis provides new insight into the chicken eggshell cuticle. J Proteomics. 2012;75(9):2697-2706. 
17. Chen X, Li X, Guo Y, Li W, Jianlou S, Xu G, Yang N, Zheng J. Impact of cuticle quality and eggshell thickness on egg antibacterial efficiency. Poult Sci. 2018;98(2):940-948.

18. Chen X, Li X, He Z, Hou Z, Xu G, Yang N, Zheng J. Comparative study of eggshell antibacterial effectivity in precocial and altricial birds using Escherichia coli. PLoS One. 2019;14(1):e220054.

19. Dunn I, Woolliams J, Wilson P, Icken W, Cavero D, Jones A, Quinlan-Pluck F, Williams G, Olori V, Bain M. Genetic variation and potential for genetic improvement of cuticle deposition on chicken eggs. Genet Sel Evol. 2019;51(25):1-13.

20. Sah N, Mishra B. Regulation of egg formation in the oviduct of laying hen. World's Poult Sci J. 2018;74(1):1-13.

21. Wang X, Liu L, Jiao H, Zhao J, Lin H. Regulation of biological clock in ovulation-laying of laying hens. Scientia Agricultura Sinica. 2018;51(16):3181-3190.

22. Yin Z, Lian L, Zhu F, Zhang Z, Hincke M, Yang N, Cheng Z. The transcriptome landscapes of ovary and three oviduct segments during chicken (Gallus gallus) egg formation. Genomics. 2020;112(1):19.

23. Marie P, Labas V, Brionne A, Harichaux G, Hennequet-Antier C, Nys Y, Gautron J. Quantitative proteomics and bioinformatic analysis provide new insight into protein function during avian eggshell biomineralization. J Proteomics. 2014;113:178-193.

24. Sun C, Xu G, Yang N. Differential Label-free Quantitative Proteomic Analysis of Avian Eggshell Matrix and Uterine Fluid Proteins Associated with Eggshell Mechanical Property. Proteomics. 2013;13:23-24.

25. Jonchere V, Réhault-Godbert S, Hennequet-Antier C, Cabau C, Sibut V, Cogburn L, Nys Y, Gautron J. Gene expression profiling to identify eggshell proteins involved in physical defense of the chicken egg. BMC genomics. 2010;11:57.

26. Brionne A, Nys Y, Hennequet-Antier C, Gautron J. Hen uterine gene expression profiling during eggshell formation reveals putative proteins involved in the supply of minerals or in the shell mineralization process. BMC genomics. 2014;15:220.

27. Du J, Hincke M, Rose-Martel M, Hennequet-Antier C, Brionne A, Cogburn L, Nys Y, Gautron J. Identifying specific proteins involved in eggshell membrane formation using gene expression analysis and bioinformatics. BMC Genomics. 2015;16:792.

28. Khan S, Wu S, Roberts J. RNA-sequencing analysis of shell gland shows differences in gene expression profile at two time-points of eggshell formation in laying chickens. BMC Genomics. 2019;20(1):89.

29. Dunn I, Bain M, Edmond A, Wilson P, Milona P, Nys Y, Gautron J, Schmutz M, Preisinger R, Waddington $\mathrm{D}$. Polymorphisms in eggshell organic matrix genes are associated with eggshell quality measurement in pedigree Rhode Island Red hens. Anim Genet. 2009;40:110-114.

30. Pertiñez S, Wilson P, Icken W, Cavero D, Bain M, Jones A, Dunn I. Transcriptome analysis of the uterus of hens laying eggs differing in cuticle deposition. BMC Genomics. 2020;21:516.

31. Kanaoka Y, Ago H, Inagaki E, Nanayama T, Miyano M, Kikuno R, Fujii Y, Eguchi N, Toh H, Urade Y, Hayaishi O. Cloning and Crystal Structure of Hematopoietic Prostaglandin D Synthase. Cell. 
1997;90(6):1085-1095.

32. Urade Y, Eguchi N. Lipocalin-type and hematopoietic prostaglandin D synthases as a novel example of functional convergence. Prostag Oth Lipid M. 2002;68-69:375-382.

33. Gross G, Imamura T, Muglia LJ. Gene knockout mice in the study of parturition. J Soc Gynecol Invest. 2000;7(2):88-95.

34. Urade Y, Hayaishi O. Prostaglandin D2 and sleep/wake regulation. Sleep Med Rev. 2011;15(6):411418.

35. Onoe H, Ueno R, Fujita I, Nishino H, Oomura Y, Hayaishi O. Prostaglandin D2, a cerebral sleepinducing substance in monkeys. Proc Natl Acad Sci USA. 1988;85:4082-4086.

36. Ohinata K, Yoshikawa M. Central prostaglandins in food intake regulation. Nutrition. 2008;24(9):798801.

37. Saito S, Tsuda H, Michimata T. Prostaglandin D2 and reproduction. Am J Reprod Immunol. 2015;47(5):295-302.

38. Hertelendy F, Yeh M, Biellier HV. Induction of oviposition in the domestic hen by prostaglandins. Gen Comp Endocrinol. 1974;22(4):529-531.

39. Hertelendy F, Biellier HV. Evidence for a physiological role of prostaglandins in oviposition by the hen. J Reprod Fertil. 1978;53(1):71-74.

40. Phaneuf S, Carrasco MP, Europe-Finner GN, Hamilton CH, López Bernal A. Multiple G proteins and phospholipase $\mathrm{C}$ isoforms in human myometrial cells: implication for oxytocin action. $\mathrm{J}$ Clin Endocrinol Metab. 1996;81(6):2098-2103.

41. Page K, Mccool W, Guidera M. Examination of the Pharmacology of Oxytocin and Clinical Guidelines for Use in Labor. Journal of Midwifery Wom Heal. 2017;62(4):425-433.

42. Kernberg A, Caughey A. Augmentation of Labor. Obstet Gyn Clin N Am. 2017;44(4):593-600.

43. Salomonis N, Cotte N, Zambon A, Pollard K, Vranizan K, Doniger S, Dolganov G, Conklin B. Identifying genetic networks underlying myometrial transition to labor. Genome Biol. 2005;6(2):R12.

44. Silvia WJ, Homanics GE. Role of phospholipase $C$ in mediating oxytocin-induced release of prostaglandin F2 alpha from ovine endometrial tissue. Prostaglandins. 1988;35(4):535-548.

45. Phillippe $M$. The relationship between oxytocin, phosphoinositide-specific phospholipase $C$, and phasic myometrial contractions. J Soc Gynecol Invest. 1994;1(1):49-54.

46. Ku CY, Qian A, Wen Y, Anwer K, Sanborn BM. Oxytocin stimulates myometrial guanosine triphosphatase and phospholipase- $C$ activities via coupling to $G$ alpha $q / 11$. Endocrinology. 1995;136(4):1509-1515.

47. Challis J, Stephen M, William G, Stephen L. Endocrine and Paracrine Regulation of Birth at Term and Preterm. Endocr Rev. 2000;21(5):514-550.

48. Norwitz ER, Robinson JN, Challis JR. The control of labor. New Engl J Med. 1999;341(9):660-666.

49. Herington JL, O'Brien C, Robuck MF, Lei W, Brown N, Slaughter JC, Paria BC, Mahadevan-Jansen A, Reese J. Prostaglandin-Endoperoxide Synthase 1 Mediates the Timing of Parturition in Mice Despite 
Unhindered Uterine Contractility. Endocrinology. 2018;159(1):490-505.

50. Fetalvero K, Zhang P, Shyu M, Young B, Hwa J, Young R, Martin K. Prostacyclin primes pregnant human myometrium for an enhanced contractile response in parturition. $\mathrm{J}$ Clin Invest. 2009;118(12):3966-3979.

51. Saito N, Shimada K, Koike TI. Interrelationship between arginine vasotocin, prostaglandin, and uterine contractility in the control of oviposition in the hen (Gallus domesticus). Gen Comp Endocrinol. 1987;67(3):342-347.

52. Aboulghar M. Role of adrenomedullin in reproduction and endometriosis. Fertil Steril. 2018;109(6):1010-1011.

53. Ross GR, Uma Y, Gangula PRR, Luckey R, Sathishkumar K, Haijun G, Madhu C, Chandra Y. Adrenomedullin Relaxes Rat Uterine Artery: Mechanisms and Influence of Pregnancy and Estradiol. Endocrinology. 2010;(9):4485-4493.

54. Thota C, Yallampalli C. Progesterone Upregulates Calcitonin Gene-Related Peptide and Adrenomedullin Receptor Components and Cyclic Adenosine 3'5'-Monophosphate Generation in Eker Rat Uterine Smooth Muscle Cell Line. Biol Reprod. 2005;72(2):416-422.

55. Wilkanowska A, Mazurowski A, Mroczkowski S, Kokoszynski D. Prolactin (PRL) and prolactin receptor (PRLR) genes and their role in poultry production traits. Folia Biol. 2014;62(1):1-8.

56. Ohkubo T, Tanaka M, Nakashima K. Molecular cloning of the chicken prolactin gene and activation by Pit-1 and cAMP-induced factor in GH3 cells. Gen Comp Endocrinol. 2000;119(2):208-216.

57. Xing G, Zhao Q, Mao J, Liu T, Wang G. Identification and characterization of goose prolactin receptor. Poult Sci. 2011;90(5):1050-1057.

58. Liu Z, Sun C, Yan Y, Li G, Shi F, Wu G, Liu A, Yang N. Genetic variations for egg quality of chickens at late laying period revealed by genome-wide association study. Sci Rep. 2018;8(1):10832-10842.

59. Reddy IJ, David CG, Singh K. Relationship between Intersequence Pauses, Laying Persistency and Concentration of Prolactin during the Productive Period in White Leghorn Hens. Asian Austral J Anima Sci. 2005;18(5):686-691.

60. Kulibaba RA, Podstreshnyi AP. Prolactin and growth hormone gene polymorphisms in chicken lines of Ukrainian selection. Cytol Genet. 2012;46(6):390-395.

61. Reddy IJ, David CG, Singh K. Influence of 2-bromo-a-ergocryptine on Plasma Prolactin, Oestradiol$17 \beta$ and Progesterone Levels in Domestic Hen. Asian Austral J Anima Sci. 2002;15(8):1103-1109.

62. Ogawa K, Matsuo S, Tojo H. Inhibitory Effects of Prolactin on Ovulation and Egg Shell Formation in the Hen. Nihon Chikusan Gakkaiho. 1977;48(7):341-346.

63. Mishra SK, Chen B, Zhu Q, Xu Z, Ning C, Yin H, Wang Y, Zhao X, Fan X, Yang M, Yang D, Ni Q, Li Y, Zhang M, Li D. Transcriptome analysis reveals differentially expressed genes associated with high rates of egg production in chicken hypothalamic-pituitary-ovarian axis. Sci Rep. 2020;10(1):5976.

64. Wang $\mathrm{C}$, Ma W. Hypothalamic and pituitary transcriptome profiling using RNA-sequencing in highyielding and low-yielding laying hens. Sci Rep. 2019;9(1):10285. 
65. Rozenboim I, Tako E, Gal-Garber O, Proudman JA, Uni Z. The effect of heat stress on ovarian function of laying hens. Poult Sci. 2007;86(8):1760-1765.

66. Steckler D, Naidoo V, Gerber D, Kähn W. Ex vivo influence of carbetocin on equine myometrial muscles and comparison with oxytocin. Theriogenology. 2012;78(3):502-509.

67. Paccamonti D, Pycock J, Taverne M, Bevers M, Weijden G, Gutjahr S, Schams D, Blouin D. PGFM response to exogenous oxytocin and determination of the half-life of oxytocin in nonpregnant mares. Equine Vet J. 1999;31(4):285-288.

68. Schwanhäusser B, Busse D, Li N, Dittmar G, Schuchhardt J, Wolf J, Chen W, Selbach M. Corrigendum: Global quantification of mammalian gene expression control. Nature. 2011;473(7374):337-342.

69. Shu Y, Hong-Hui L. Transcription, translation, degradation, and circadian clock. Biochem Bioph Res Co. 2004;321(1):1-6.

70. Karim M, Donal O, Upton PD, Small CJ, Ghatei MA, Byfield PH, Bloom SR. Circulating adrenomedullin does not regulate systemic blood pressure but increases plasma prolactin after intravenous infusion in humans: a pharmacokinetic study. J Clin Endocr Metab. 1997;82(1):95-100.

71. Nys $Y$. Relationships between age, shell quality and individual rate and duration of shell formation in domestic hens. Br Poult Sci. 1986;27(2):253-259.

72. Sun C, Qu L, Yi G, Yuan J, Yang N. Genome-wide association study revealed a promising region and candidate genes for eggshell quality in an F2 resource population. BMC Genomics. 2015;16(1):565.

73. Radwan LM. Eggshell quality: a comparison between Fayoumi, Gimieizah and Brown Hy-Line strains for mechanical properties and ultrastructure of their eggshells. Anim Prod Sci. 2015;56(5):908-912.

74. Li W, Chen X, Yuan ZY, Yu Y, Wu G, Shi F, Yang N, Xu G, Zheng J. Genetic Characterization of Cuticle and Its Association with Eggshell Quality Traits. Chin J Anim Vet Sci. 2018;49(4):659-666.

75. Arad Z, Eylath U, Ginsburg M, Eyal-Giladi H. Changes in uterine fluid composition and acid-base status during shell formation in the chicken. Am J Physiol. 1989;257(42):R732-R737.

76. Nakada T, Koga O. Stimulation of secretion of shell gland fluid and calcium by the presence of ovum or ovum-like mass containing artificial yolk in the oviduct uterus of the hen. $\mathrm{J}$ Poult Sci. 2008;27(1):21-28.

77. Gautron J, Hincke MT, Nys Y. Precursor matrix proteins in the uterine fluid change with stages of eggshell formation in hens. Connect Tissue Res. 1997;36(3):195-210.

78. Marie P, Labas V, Brionne A, Harichaux G, Hennequet-Antier C, Nys Y, Gautron JL. Quantitative proteomics and bioinformatic analysis provide new insight into protein function during avian eggshell biomineralization. J Proteomics. 2015;113:178-193.

79. Hincke MT, Yves N, Joel G. The Role of Matrix Proteins in Eggshell Formation. J Poult Sci. 2010;47(3):208-219.

80. Dunn IC, Rodríguez-Navarro AB, Mcdade K, Schmutz M, Preisinger R, Waddington D, Wilson PW, Bain MM. Genetic variation in eggshell crystal size and orientation is large and these traits are correlated 
with shell thickness and are associated with eggshell matrix protein markers. Anim Genet. 2012;43(4):410-418.

81. Rose-Martel M, Du J, Hincke MT. Proteomic analysis provides new insight into the chicken eggshell cuticle. J Proteomics. 2012;75(9):2697-2706.

82. Mik Ík I, Ergang P, Pácha J. Proteomic analysis of chicken eggshell cuticle membrane layer. Anal Bioanal Chem. 2014;406(29):7633-7640.

83. Zhang Q, Zhu F, Liu L, Zheng CW, Wang DH, Hou ZC, Ning ZH. Integrating transcriptome and genome re-sequencing data to identify key genes and mutations affecting chicken eggshell qualities. PLoS One. 2015;10(5):e125890.

84. Hennessey JA, Wei EQ, Pitt GS. Fibroblast growth factor homologous factors modulate cardiac calcium channels. Circ Res. 2013;113(4):381-388.

85. Wang X, Tang H, Wei EQ, Wang Z, Yang J, Yang R, Wang S, Zhang Y, Pitt GS, Zhang H, Wang C. Conditional knockout of Fgf13 in murine hearts increases arrhythmia susceptibility and reveals novel ion channel modulatory roles. J Mol Cell Cardiol. 2017;104:63-74.

86. Burel S, Coyan FC, Lorenzini M, Meyer MR, Lichti CF, Brown JH, Loussouarn G, Charpentier F, Nerbonne JM, Townsend RR, Maier LS, Marionneau C. C-terminal phosphorylation of $\mathrm{Na}(\mathrm{V}) 1.5$ impairs FGF13-dependent regulation of channel inactivation. J Biol Chem. 2017;292(42):1743117448.

87. Richards J, Gumz M. Mechanism of the circadian clock in physiology. Am J Physiol-Reg I. 2013;304(12):R1053-R1064.

88. Bell-Pedersen D, Cassone V, Earnest D, Golden S, Hardin P, Thomas T, Zoran M. Circadian rhythms from multiple oscillators: lessons from diverse organisms. Nat Rev Genet. 2005;6(7):544-556.

89. Underwood H, Steele CT, Zivkovic B. Circadian organization and the role of the pineal in birds. Microsc Res Techniq. 2001;53(1):48-62.

90. Yoshimura T, Suzuki Y, Makino E, Suzuki T, Ebihara S. Molecular analysis of avian circadian clock genes. Mol Brain Res. 2000;78(1):207-215.

91. Zhang ZC, Wang Y, Li L, Yin H, Li D, Wang Y, Zhao X, Liu Y, Zhu Q. Circadian clock genes are rhythmically expressed in specific segments of the hen oviduct. Poult Sci. 2016;95(7):1653-1659.

92. Olson DM, Biellier HV, Hertelendy F. Shell gland responsiveness to prostaglandins F2alpha and E1 and to arginine vasotocin during the laying cycle of the domestic hen (Gallus domesticus). Gen Comp Endocrinol. 1978;36(4):559-565.

93. Ko $\mathrm{CH}$, Takahashi JS. Molecular components of the mammalian circadian clock. Hum Mol Genet. 2006;15:R271-R277.

94. Percie DSN, Hurst V, Ahluwalia A, Alam S, Avey MT, Baker M, Browne WJ, Clark A, Cuthill IC, DirnagI U, Emerson M, Garner P, Holgate ST, Howells DW, Karp NA, Lazic SE, Lidster K, MacCallum CJ, Macleod M, Pearl EJ, Petersen OH, Rawle F, Reynolds P, Rooney K, Sena ES, Silberberg SD, Steckler T, Würbel H. The ARRIVE guidelines 2.0: Updated guidelines for reporting animal research. PLoS Biol. 2020;18(7):e3000410. 
95. Pertea M, Kim D, Pertea GM, Leek JT, Salzberg SL. Transcript-level expression analysis of RNA-seq experiments with HISAT, StringTie and Ballgown. Nat Protoc. 2016;11(9):1650-1667.

96. Kim D, Langmead B, Salzberg SL. HISAT: a fast spliced aligner with low memory requirements. Nat Methods. 2015;12(4):357-360.

97. Love MI, Huber W, Anders S. Moderated estimation of fold change and dispersion for RNA-seq data with DESeq2. Genome Biol. 2014;15(12):550.

98. Huang DW, Sherman BT, Lempicki RA. Systematic and integrative analysis of large gene lists using DAVID bioinformatics resources. Nat Protoc. 2009;4(1):44-57.

99. Huang DW, Sherman BT, Lempicki RA. Bioinformatics enrichment tools: paths toward the comprehensive functional analysis of large gene lists. Nucleic Acids Res. 2009;37(1):1-13.

100. Ritchie ME, Phipson B, Wu D, Hu Y, Law CW, Shi W, Smyth GK. limma powers differential expression analyses for RNA-sequencing and microarray studies. Nucleic Acids Res. 2015;43(7):e47.

101. Livak KJ, Schmittgen TD. Analysis of Relative Gene Expression Data Using Real-Time Quantitative PCR and the 2- $\triangle \Delta C T$ Method. Methods. 2001;25(4):402-408.

102. Duan Z, Sun C, Shen M, Wang K, Yang N, Zheng J, Xu G. Genetic architecture dissection by genomewide association analysis reveals avian eggshell ultrastructure traits. Sci Rep. 2016;6:28836.

\section{Figures}




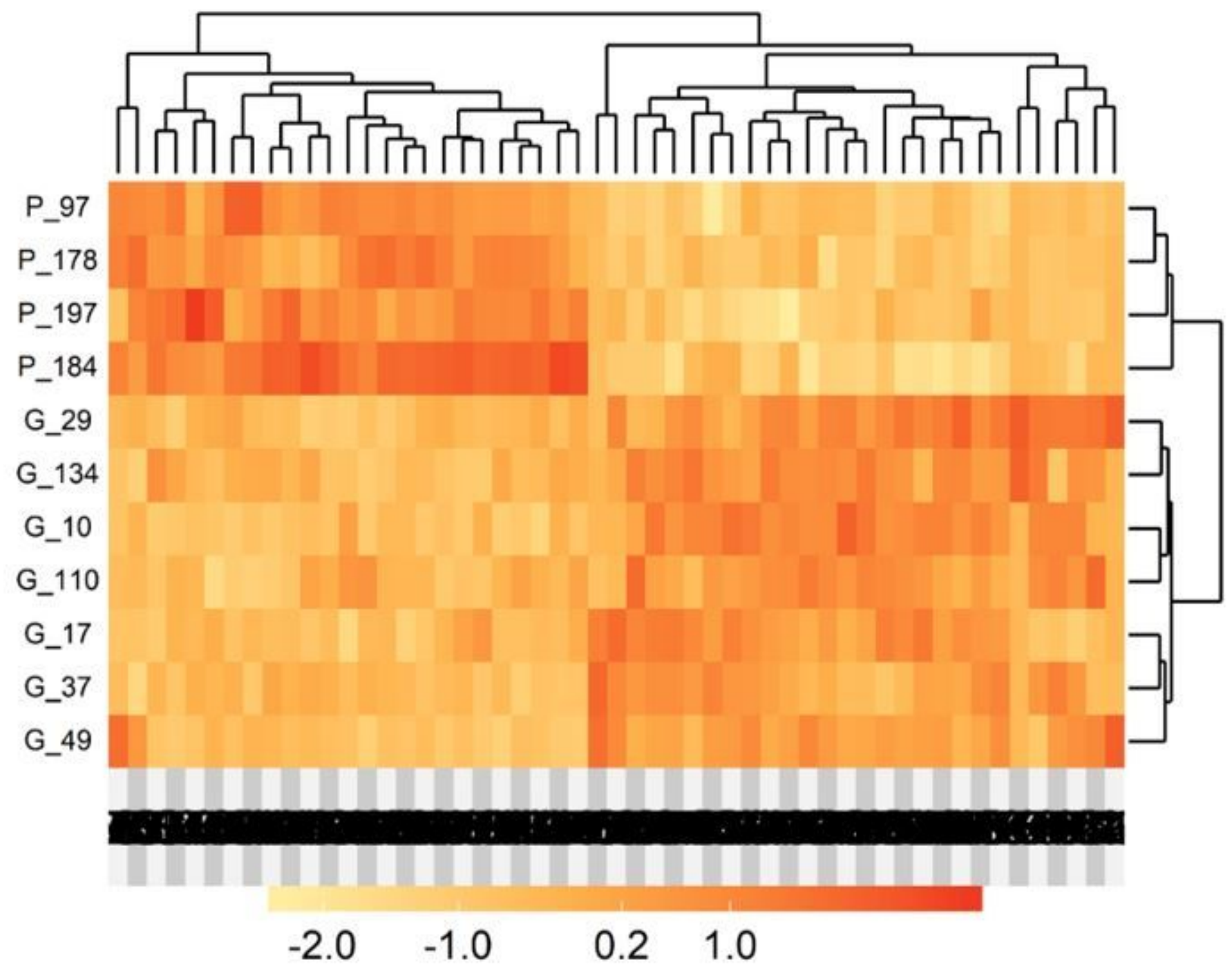

Figure 1

Heatmap of the DEGs between GC and PC hen uterus during cuticle deposition from the transcriptomic analysis. GC, good cuticle; PC, poor cuticle. 


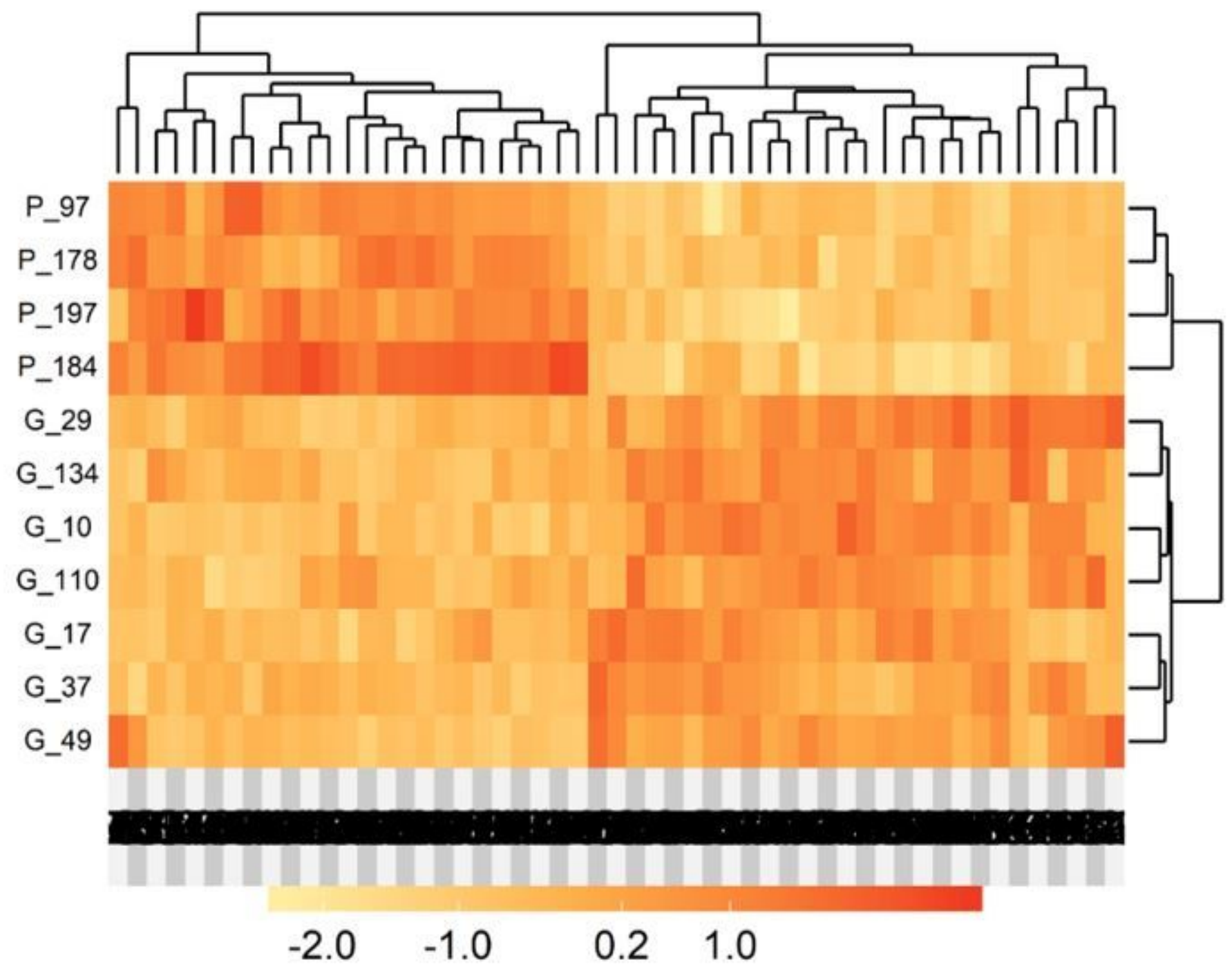

Figure 1

Heatmap of the DEGs between GC and PC hen uterus during cuticle deposition from the transcriptomic analysis. GC, good cuticle; PC, poor cuticle. 


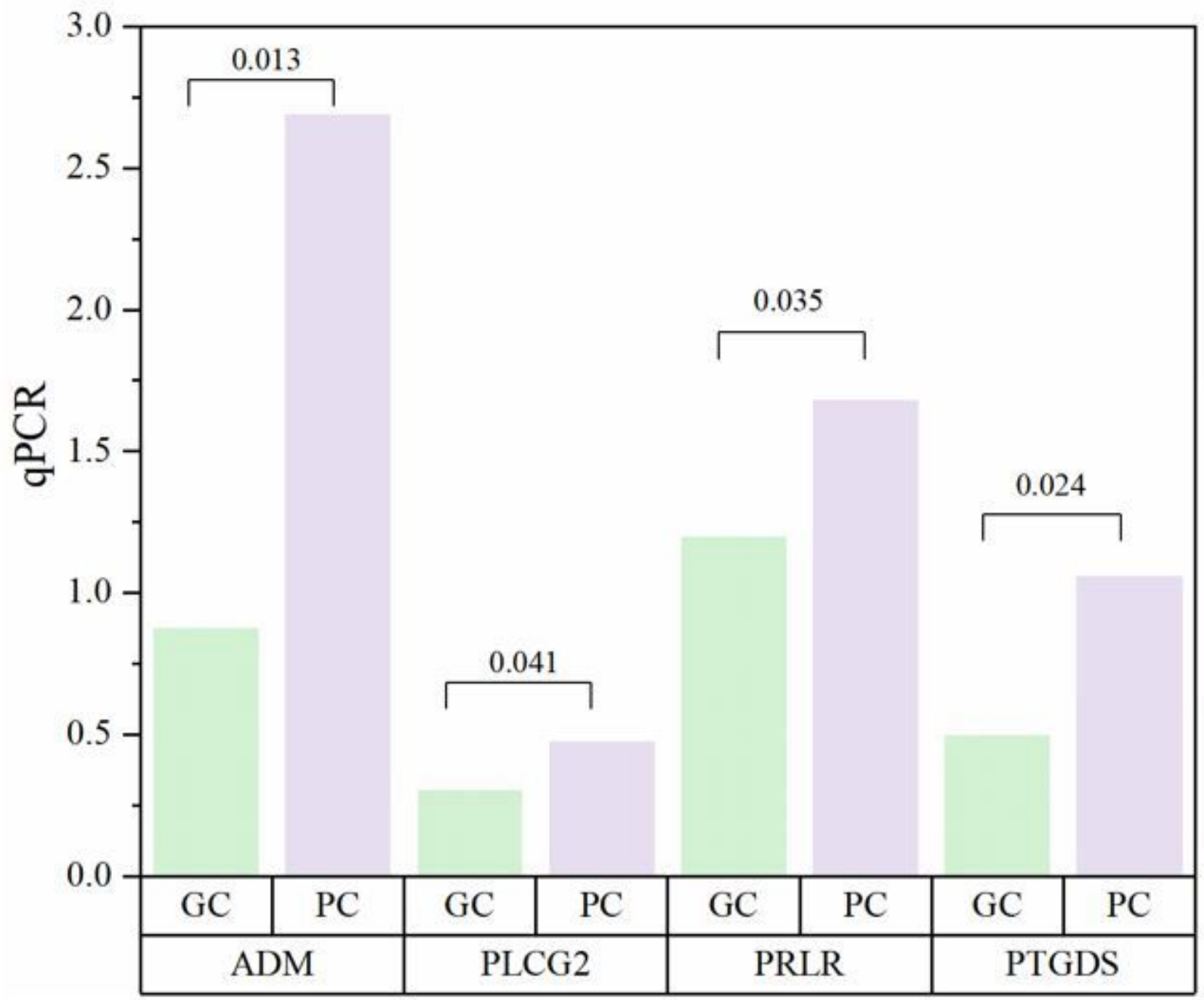

Figure 2

Validation of the DEGs of GC vs PC hen uterus during cuticle deposition from the transcriptomic analysis. The qPCR was performed to quantify the the relative gene expression level based on the 2- $\triangle \triangle C T$ method. For gene expression data normalization, GAPDH was used as a reference gene. Fold changes between the GC (good cuticle) and PC (poor cuticle) group were calculated for the genes ADM, PLCG2, PRLR and PTGDS. The $Y$ axis shows the fold changes. 


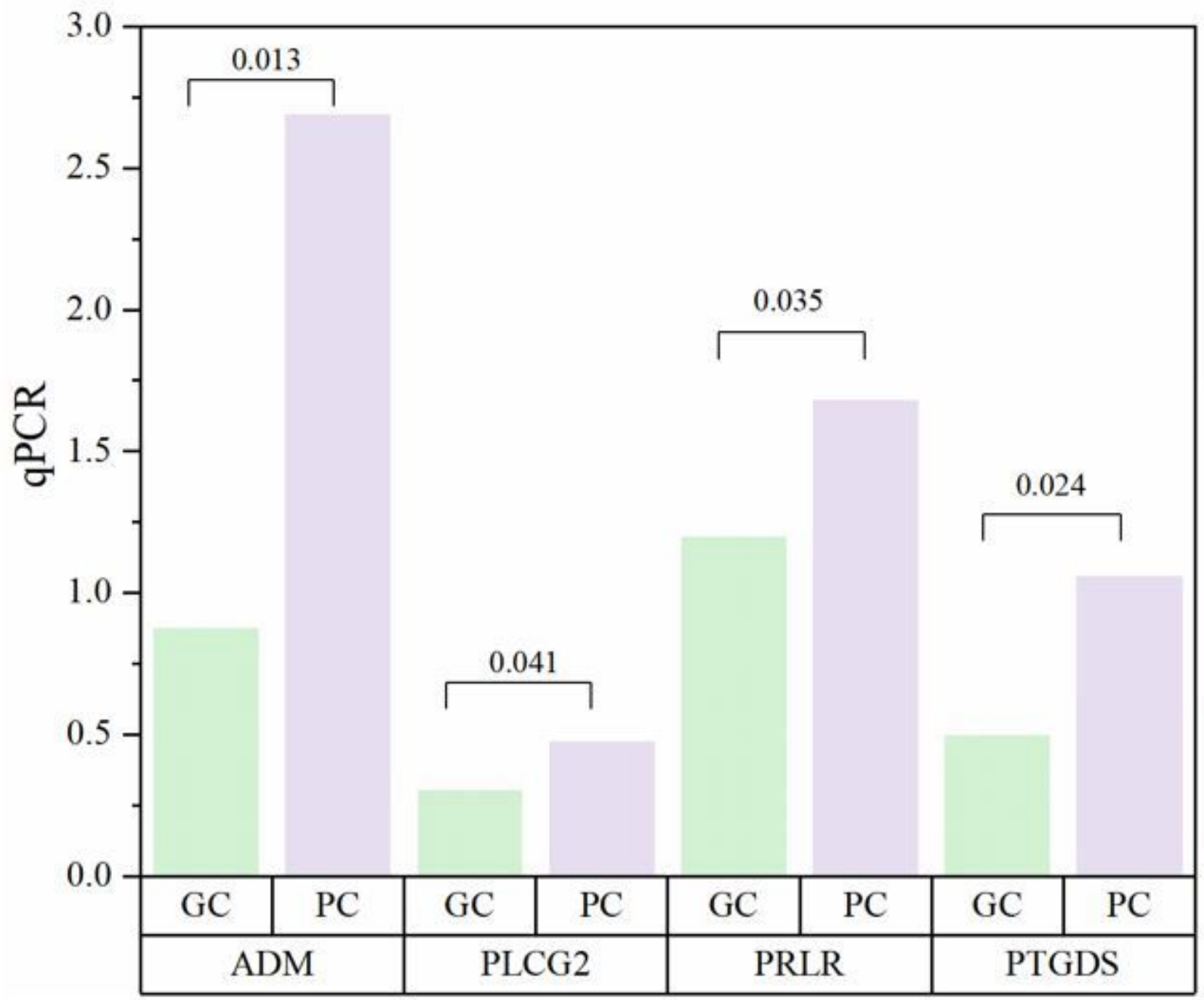

Figure 2

Validation of the DEGs of GC vs PC hen uterus during cuticle deposition from the transcriptomic analysis. The qPCR was performed to quantify the the relative gene expression level based on the 2- $\triangle \triangle C T$ method. For gene expression data normalization, GAPDH was used as a reference gene. Fold changes between the GC (good cuticle) and PC (poor cuticle) group were calculated for the genes ADM, PLCG2, PRLR and PTGDS. The $Y$ axis shows the fold changes. 


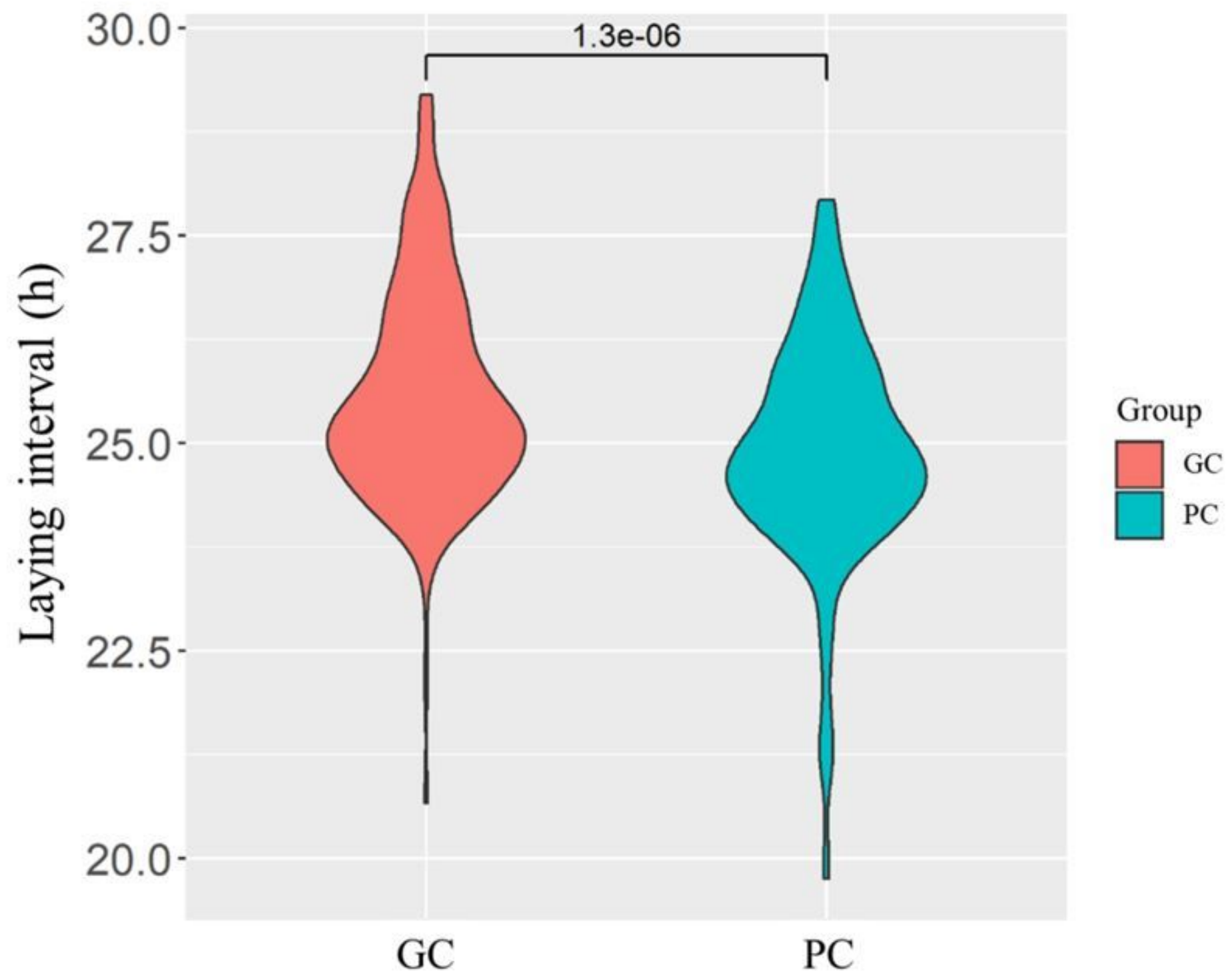

Figure 3

Laying interval of GC and PC group hens. The laying interval between two consecutive ovipositions was determined (at least 4 ovipositions per hen) for GC and PC group hens at 28-week old (GC $25.64 \pm 1.23$ vs PC $24.94 \pm 1.12$, h; $n=60 ; P<0.01)$. 


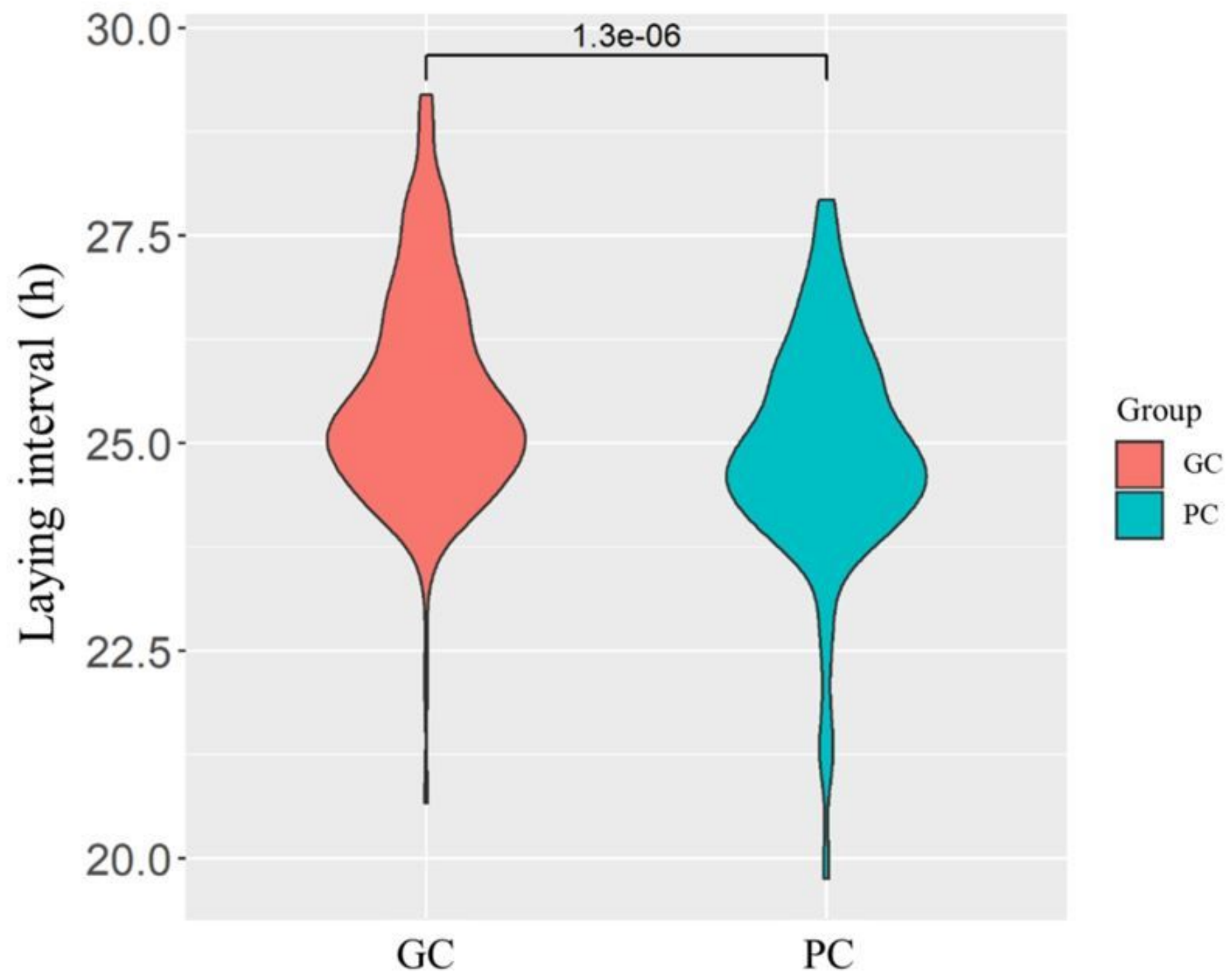

Figure 3

Laying interval of GC and PC group hens. The laying interval between two consecutive ovipositions was determined (at least 4 ovipositions per hen) for GC and PC group hens at 28-week old (GC $25.64 \pm 1.23$ vs PC $24.94 \pm 1.12$, h; $n=60 ; P<0.01)$. 

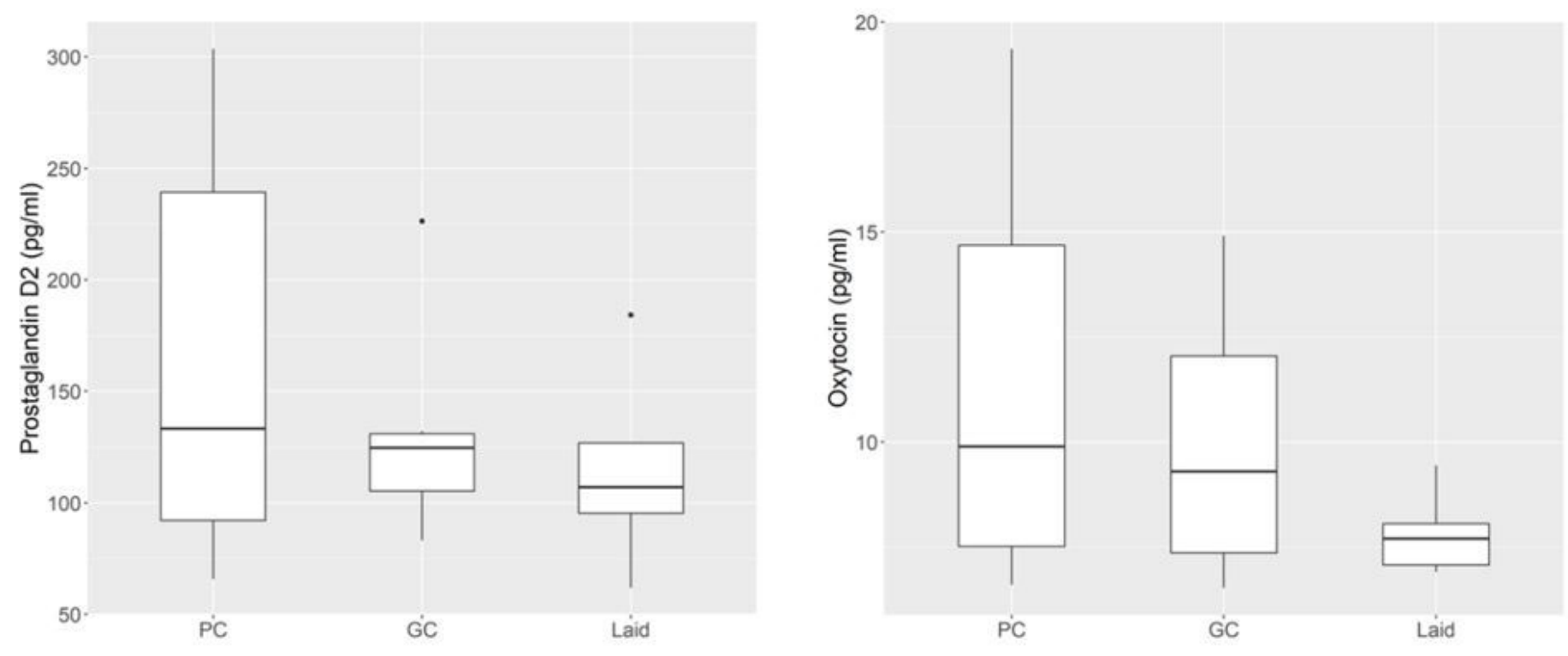

\section{Figure 4}

The concentrations of prostaglandin D2 and oxytocin in hen serum. GC, good cuticle quality hen $1 \mathrm{~h}$ before oviposition; PC, pore cuticle quality hen $1 \mathrm{~h}$ before oviposition; Laid, good cuticle quality hen $0.5 \mathrm{~h}$ after oviposition.
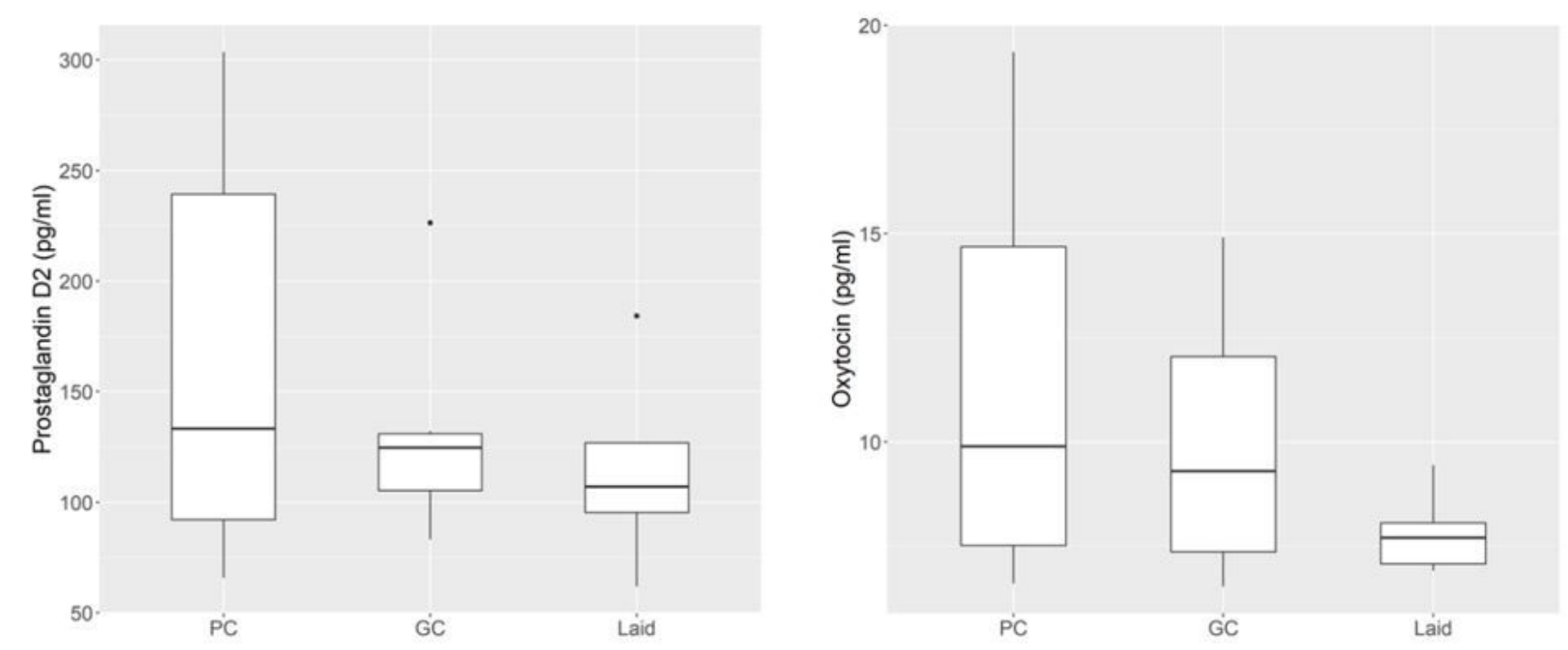

\section{Figure 4}

The concentrations of prostaglandin D2 and oxytocin in hen serum. GC, good cuticle quality hen $1 \mathrm{~h}$ before oviposition; PC, pore cuticle quality hen $1 \mathrm{~h}$ before oviposition; Laid, good cuticle quality hen $0.5 \mathrm{~h}$ after oviposition. 

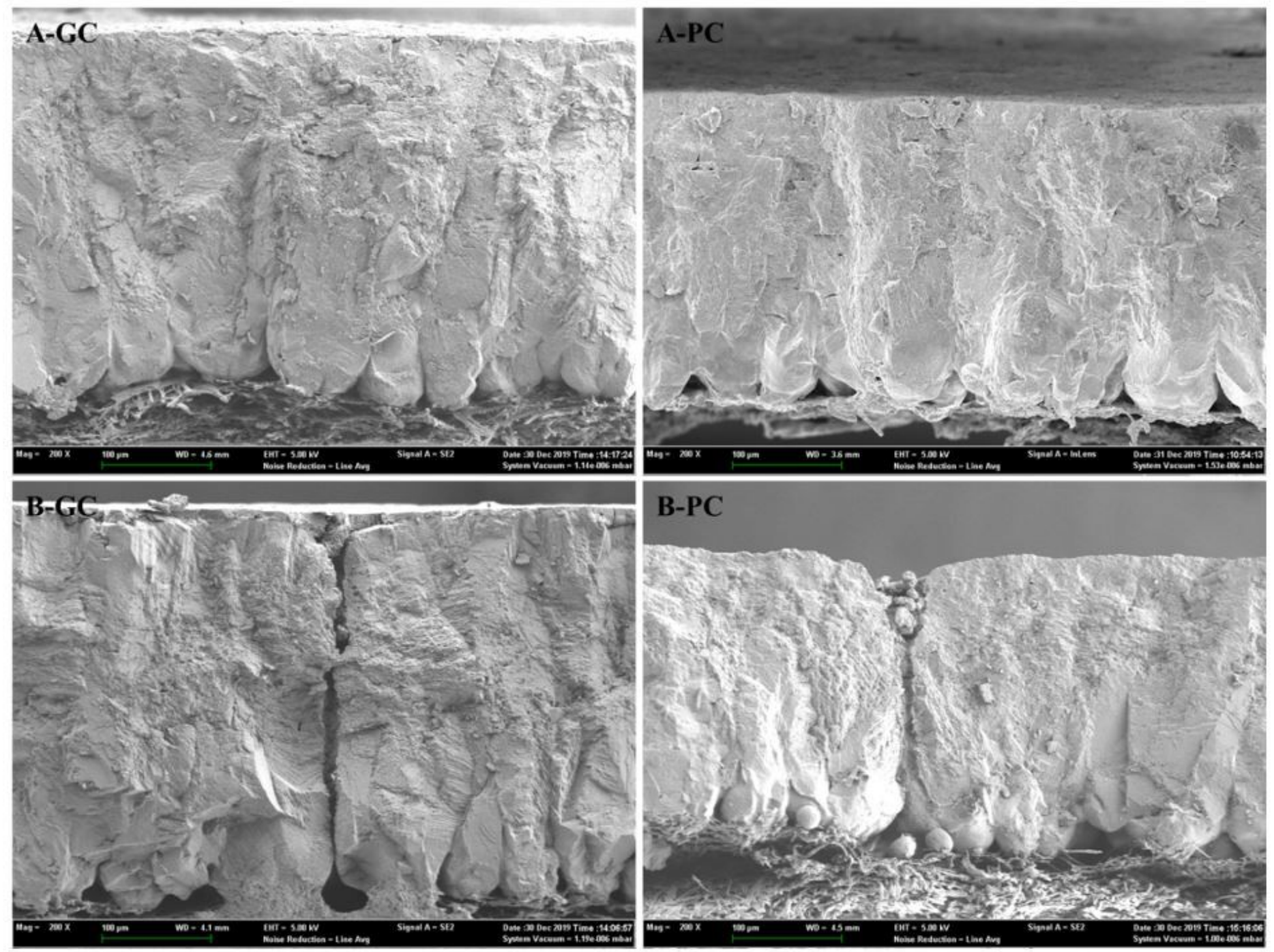

\section{Figure 5}

Eggshell ultrastructure of GC and PC group eggs by scanning electron microscope (SEM) $(200 \times)$. GC, eggshells with good cuticle; $\mathrm{PC}$, eggshells with poor cuticle; $A$ and $B$, eggshell ultrastructure without and with a gas pore, respectively. 

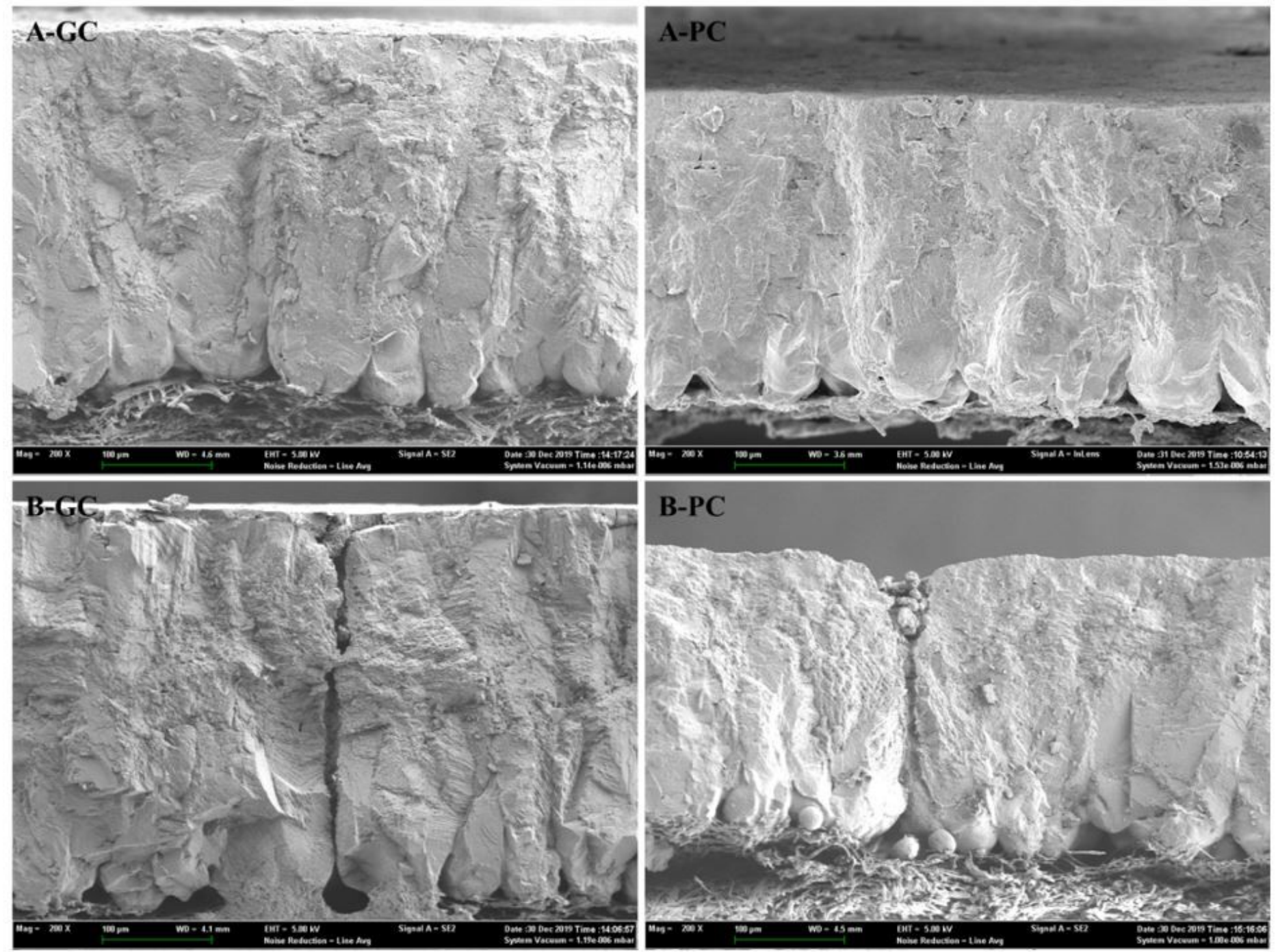

\section{Figure 5}

Eggshell ultrastructure of GC and PC group eggs by scanning electron microscope (SEM) $(200 \times)$. GC, eggshells with good cuticle; $\mathrm{PC}$, eggshells with poor cuticle; $A$ and $B$, eggshell ultrastructure without and with a gas pore, respectively.

\section{Supplementary Files}

This is a list of supplementary files associated with this preprint. Click to download.

- Additionalfile1FigureS1.doc

- Additionalfile1Figures1.doc

- Additionalfile2TableS1.xlsx

- Additionalfile2TableS1.xlsx

- Additionalfile3TableS2.xIsx 
- Additionalfile3TableS2.xIsx

- Additionalfile4TableS3.docx

- Additionalfile4TableS3.docx 